\title{
Article \\ A New Calcium(II)-Based Substitute for Enrofloxacin with Improved Medicinal Potential
}

\author{
Hou-Tian Yan ${ }^{1,+}{ }^{,}$, Rui-Xue Liu ${ }^{1,+}$, Qi-Zhen Yang ${ }^{1,+}{ }^{+}$, Yan-Cheng Liu ${ }^{1, *}\left(\mathbb{D}\right.$, Hong-Chang Li ${ }^{1}$, Rui-Feng Guo ${ }^{1}$, \\ Lin-Hua $\mathrm{Wu}^{2}{ }^{2}$, Li-Min Liu ${ }^{2}$ and Hong Liang ${ }^{1, *}$ \\ 1 School of Chemistry \& Pharmaceutical Sciences, State Key Laboratory for the Chemistry and Molecular \\ Engineering of Medicinal Resources, Guangxi Normal University, Guilin 541004, China; \\ yanhoutian@aliyun.com (H.-T.Y.); 2018110012@stu.gxnu.edu.cn (R.-X.L.); \\ 2017010327@stu.gxnu.edu.cn (Q.-Z.Y.); 2019010318@stu.gxnu.edu.cn (H.-C.L.); \\ 2018011084@stu.gxnu.edu.cn (R.-F.G.) \\ 2 College of Pharmacy, Guangxi Medical University, Nanning 530021, China; wlh626@sohu.com (L.-H.W.); \\ liulimin_gxykdx@hotmail.com (L.-M.L.) \\ * Correspondence: ycliu@gxnu.edu.cn (Y.-C.L.); hliang@gxnu.edu.cn (H.L.); \\ Tel./Fax: +86-773-2535678 (Y.-C.L. \& H.L.) \\ + These authors contributed equally to this work.
}

check for updates

Citation: Yan, H.-T.; Liu, R.-X.; Yang, Q.-Z.; Liu, Y.-C.; Li, H.-C.; Guo, R.-F.; Wu, L.-H.; Liu, L.-M.; Liang, H. A New Calcium(II)-Based Substitute for Enrofloxacin with Improved Medicinal Potential. Pharmaceutics 2022, 14, 249. https://doi.org/ 10.3390/pharmaceutics14020249 Academic Editors: Jaehwi Lee and Tristan Montier

Received: 13 November 2021 Accepted: 18 January 2022

Published: 21 January 2022

Publisher's Note: MDPI stays neutral with regard to jurisdictional claims in published maps and institutional affiliations.

Copyright: (C) 2022 by the authors. Licensee MDPI, Basel, Switzerland. This article is an open access article distributed under the terms and conditions of the Creative Commons Attribution (CC BY) license (https:/ / creativecommons.org/licenses/by/ $4.0 /)$.

\begin{abstract}
Enrofloxacin (EFX) reacting with $\mathrm{Ca}(\mathrm{II})$ afforded a new complex, $\left[\mathrm{Ca}(\mathrm{EFX})_{2}\left(\mathrm{H}_{2} \mathrm{O}\right)_{4}\right](\mathrm{EFX}-\mathrm{Ca})$, which was structurally characterized both in solid and solution chemistry. E. coli and $S$. typhi were tested to be the most sensitive strains for EFX-Ca. The LD 50 value of EFX-Ca in mice was $7736 \mathrm{mg} / \mathrm{kg}$, implying the coordination of EFX to $\mathrm{Ca}$ (II) effectively reduced its acute toxicity. EFX-Ca also decreased the plasma-binding rate and enhanced the drug distribution in rats along with longer elimination halflife. EFX-Ca also showed similar low in vivo acute toxicity and higher anti-inflammation induced by $\mathrm{H}_{2} \mathrm{O}_{2}$ or $\mathrm{CuSO}_{4}$ in zebrafish, with reactive oxygen species (ROS)-related elimination. The therapeutic effects of EFX-Ca on two types (AA and 817) of E. coli-infected broilers were also better than those of EFX, with cure rates of $78 \%$ and $88 \%$, respectively. EFX-Ca showed promise as a bio-safe metal-based veterinary drug with good efficacy and lower toxicity.
\end{abstract}

Keywords: enrofloxacin; calcium(II) complex; veterinary drug; antibacterial activity; animal chemotherapy

\section{Introduction}

Common veterinary drugs play an important role in animal husbandry because of their preventive and therapeutic benefits. Antibacterial and bactericidal drugs against animal diseases account for a significant proportion of these veterinary drugs. Quinolones are a class of synthetic antibacterial drugs that have a characteristic structural skeleton of a 4-quinolone ring [1,2]. Since the nalidixic acid antibacterial agent was first discovered in 1962 in the United States by Lesher et al., quinolone-type antibacterial drugs have been extensively developed, studied, and used in the treatment of animal diseases [3-5]. The third-generation quinolone antibacterial drugs, named fluoquinolones (FQNs), were developed successfully in the 1980s. These FQNs not only introduce the fluorine group into the structural skeleton of quinolones (as 6-F) but also introduce the piperazinyl group [1,6]. Such structural improvements have enhanced drug penetration into the bacterial cells to increase the antibacterial efficacy of these drugs. This has significantly improved the bioavailability of such drugs in vivo and has extended the antibacterial range of FQNs compared with the previous two generations. Unlike other common antibiotics, FQNs target bacterial DNA and DNA gyrase [7,8]. They can effectively inhibit DNA cyclotron enzymes in bacterial cells, thus causing irreversible damage to bacterial DNA and blocking the division of bacterial cells [7,9]. In addition, FQNs are not affected by plasmid-mediated 
drug resistance and therefore have no cross-resistance to many antimicrobial drugs. Therefore, the cross-resistance between FQNs and other types of antimicrobial agents was not common for most plasmid-mediated bacterial resistance before the past two decades [10]. Some FQNs, such as enrofloxacin (EFX), lomefloxacin, and sarafloxacin, have been used clinically as veterinary drugs to treat animal diseases [11]. EFX is a typical representative of FQNs that is used specifically as a veterinary drug and shows a broad-spectrum antibacterial activity [12-14]. In addition, EFX shows an even better bactericidal effect and thus greatly reduces the toxicity to the central nervous system [15]. EFX can also create a suicidal factor or can destabilize GyrA dimer in bacteria, which induces chromosome fragmentation [16]. Conversely, EFX also has shown moderate acute toxicity and its most common side effects include inducing tendinopathy and cartilage damage and affecting the reproductive system. Furthermore, with a significantly increased application of this kind of antibiotic worldwide, especially in China, the inexorable increase in resistance, even cross-resistance, of these drugs has become a significant problem $[17,18]$. This is mainly due to the mutations in the gyrA gene, a target of FQNs, further followed by the enhancement of the active pumping mechanism of the bacterial cells [19]. Therefore, the improvement and regulation of these classic drugs are important aspects of drug improvement.

Globally, all types of metal complexes have been studied as potential antibacterial drugs for dozens of years and have shown their unique effects and prospects for treating diseases [20-24]. Some metal complexes of FQNs have also been synthesized and evaluated [25-27]. Unlike the original FQNs, some of these metal complexes have exhibited better therapeutic effects and higher inhibiting abilities of bacterial resistance. Nevertheless, it is still necessary to consider the toxic side effects with regard to the heavy metal centers of these metal complexes.

Calcium is one of the most important essential elements in the world, and it is also one of the indispensable elements in organisms. It plays an important role in the activities of life processes such as physiological activities, reproduction, immunity, and neural activity [28-30]. Compared with other transition metal complexes, far fewer reports have focused on the calcium complexes in the field of traditional metal complex research. This may be attributed to the fact that calcium has a saturated electronic structure that belongs to stearic acid, and as such, it tends to form ionic compounds, or calcium salts, but not calcium complexes [31]. Calcium plays an important role in the body. However, as proven in previous studies, the functioning of calcium in the body is closely related to the coordination binding state with different bio-ligands [32]. Therefore, calcium as a biosafe metal center especially in vivo has great appeal in the research and development of metal complexes and potential metal-based drugs.

Our previous work reported for the first time the calcium complex of a FQN drug (marbofloxacin). The results showed that this complex effectively reduced the toxicity in vivo while maintaining its antibacterial activity. The biological safety of the calcium complex of marbofloxacin suggested its medicinal potential. As a targeted potential veterinary drug, however, the achieved studies on this calcium(II) complex are not sufficiently in-depth. In addition, related pharmacokinetic studies and clinical therapeutic effects have also not been involved [32]. Conversely, the high price of marbofloxacin has resulted in the high expected cost of this calcium complex in clinical use, contributing to its poor market prospects as a potential veterinary drug. On the premise of maintaining similar antibacterial efficacy, EFX is only $1 / 20$ th of the cost of marbofloxacin, and its application in the veterinary market is predominant. Therefore, it is more attractive to study the synthesis and properties of a new calcium(II) complex of EFX, and to conduct pharmacokinetic studies and evaluate its clinical therapeutic effect for livestock on this basis, which has shown much better research value and application prospects. Therefore, in this study, we synthesized and structurally characterized EFX, a new calcium(II) complex of EFX, as a more promising metal-based substitute for the classic FQNs in potential clinical applications. To explore its medicinal prospects as a new type of metal-based veterinary drug, we conducted preferential ex- 
periments on the bacteriostatic, acute toxicity, and pharmacokinetic effects, as well as its quasi-clinical therapeutic effects, on broilers in comparison with EFX.

\section{Results and Discussion}

\subsection{Structural Characterization of EFX-Ca}

As shown in Figure 1, the calcium(II) complex of EFX, $\left[\mathrm{Ca}(\mathrm{EFX})_{2}\left(\mathrm{H}_{2} \mathrm{O}\right)_{4}\right] \cdot \mathrm{H}_{2} \mathrm{O}(\mathrm{EFX}$ $\mathrm{Ca})$, crystalized in a monoclinic system with space group $\mathrm{C} 2 / \mathrm{c}$. The central $\mathrm{Ca}$ (II) adopted an eight-coordinated geometry, in which two deprotonated EFX chelated to $\mathrm{Ca}$ (II) by the 4-carbonyl $\mathrm{O}$ and the deprotonated 3-carboxyl O. Two EFX located in the cis- form, and four $\mathrm{H}_{2} \mathrm{O}$ molecules coordinated to $\mathrm{Ca}(\mathrm{II})$ on the other side to form a dodecahedral configuration. Furthermore, the whole complex crystallized in the form of mirror symmetry. Thus, one EFX ligand and two water molecules located at the position of the mirror images of another EFX ligand and the other two water molecules of this dodecahedral complex, with the same bond lengths and bond angles. As shown in Supplementary Materials Figure S1 (ESIt), the packing diagram of the crystal structure of EFX-Ca viewed along the b-axis of the unit cell demonstrated the three-dimensional supramolecular structure of EFX-Ca consolidated by the $\mathrm{C}-\mathrm{H} \cdots \mathrm{O}$ hydrogen bonding and $\pi-\pi$ stacking interactions between the neighboring EFX ligands. Note also that the entire EFX-Ca molecule formed as electrically neutral based on the deprotonation on the 3-carboxyl group of each EFX ligand. The primary crystallized data and the refinement parameters for the crystal structure of EFX-Ca are given in Table 1. The selected bond lengths $(\AA)$ and bond angles $\left(^{\circ}\right)$ for EFX-Ca are listed in Table S1.

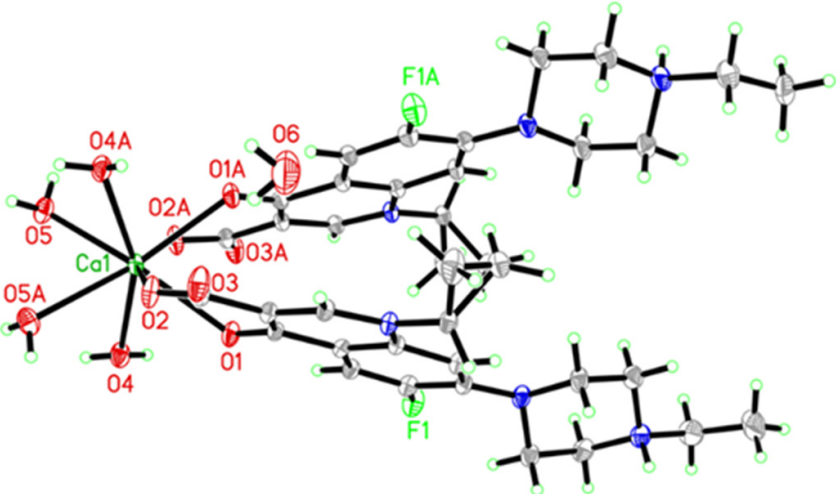

Figure 1. The ORTEP drawing for the crystal structure of EFX-Ca.

Table 1. Crystallographic and refinement parameters for EFX-Ca.

\begin{tabular}{|c|c|}
\hline Empirical Formula & $\mathrm{C}_{38} \mathrm{H}_{53} \mathrm{CaF}_{2} \mathrm{~N}_{6} \mathrm{O}_{11}$ \\
\hline Formula weight & 847.94 \\
\hline Temperature / $K$ & 296.15 \\
\hline Crystal system & Monoclinic \\
\hline Space group & $\mathrm{C} 2 / \mathrm{c}$ \\
\hline$a / \AA, b / \AA, c / \AA$ & $14.891(3), 26.250(5), 10.710(2)$ \\
\hline$\alpha /^{\circ}, \beta /^{\circ}, \gamma /^{\circ}$ & $90.00,102.825(3), 90.00$ \\
\hline Volume $/ \AA^{3}$ & $4081.9(14)$ \\
\hline Z & 4 \\
\hline$\rho_{\text {calc }} / \mathrm{mg} \mathrm{mm}^{-3}$ & 1.380 \\
\hline$\mu / \mathrm{mm}^{-1}$ & 0.229 \\
\hline$F(000)$ & 1796 \\
\hline Crystal size $/ \mathrm{mm}^{3}$ & $0.40 \times 0.20 \times 0.12$ \\
\hline $2 \theta$ range for data collection & 3.1 to $52.74^{\circ}$ \\
\hline Index ranges & $-18 \leq h \leq 18,-32 \leq k \leq 32,-13 \leq l \leq 13$ \\
\hline Reflections collected & 24,569 \\
\hline Independent reflections & $4187[R($ int $)=0.0336]$ \\
\hline Data/restraints/parameters & $4187 / 9 / 279$ \\
\hline Goodness-of-fit on $F^{2}$ & 1.056 \\
\hline Final $R$ indexes $[I>2 \sigma(I)]$ & $R_{1}=0.0384, w R_{2}=0.1116$ \\
\hline Final $R$ indexes [all data] & $R_{1}=0.0487, w R_{2}=0.1200$ \\
\hline Largest diff. peak/hole /e $\AA^{-3}$ & $0.360 /-0.512$ \\
\hline
\end{tabular}




\subsection{Determination on the Water Solubility}

Furthermore, we also examined the water solubility of EFX-Ca, in comparison with EFX, by UV-Vis spectral analysis of the prepared aqueous solution, based on the LambertBeer law. As shown in Figure S2 (left) (ESIt), we found that a 30× dilution of the saturated aqueous solution of EFX gave the peak absorbance at $273 \mathrm{~nm}$. According to the LambertBeer law based on the standard line of EFX derived from a series of working solutions prepared in different concentrations of EFX (Figure S2 (right) (ESIt)), we determined the water solubility of EFX to be $0.2042 \mathrm{mg} / \mathrm{mL}$. Using the same measuring method based on the Lambert-Beer law, the coordinated EFX-Ca showed a more satisfying water solubility, as shown in Figure 2. Thus, we calculated and determined the value of the water solubility of EFX-Ca to be $0.46 \mathrm{mg} / \mathrm{mL}$, which was more than twice that of EFX. The enhancement of the water solubility of EFX-Ca could be attributed partly to the formation of the charged species of EFX-Ca, as suggested by the results of ESI-MS. In practical applications, moderate water solubility is important for veterinary drugs, so this result provided a positive result for EFX-Ca and holds significant benefits for its potential druggability index.
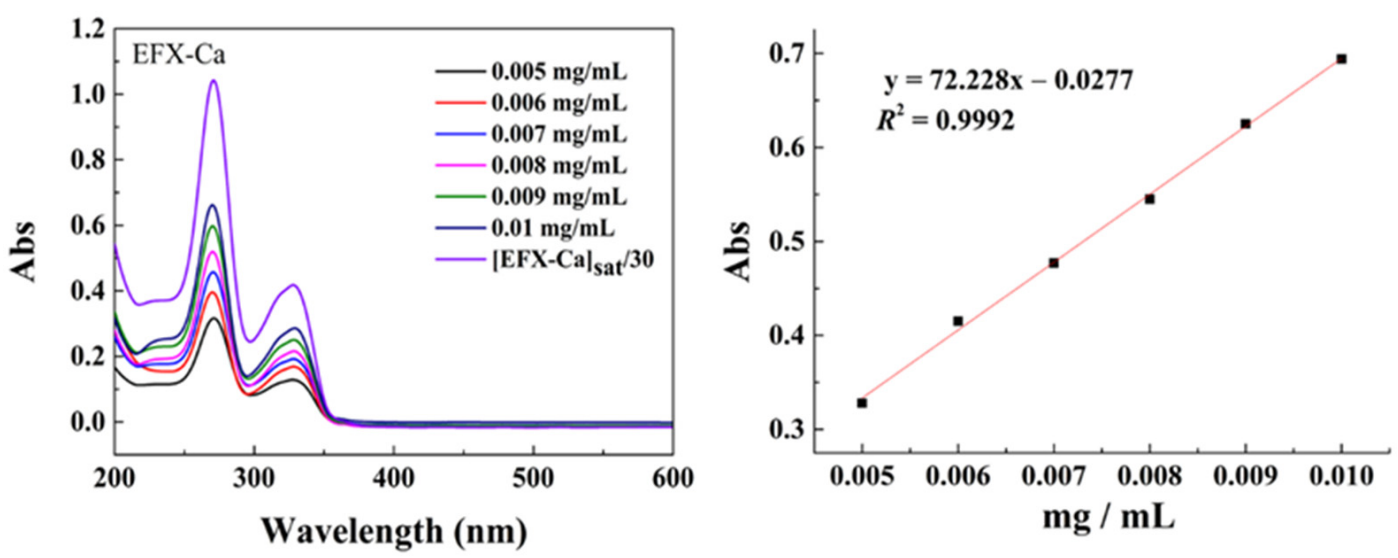

Figure 2. The water solubility of EFX-Ca at room temperature was determined by the LambertBeer law based on the standard line of the water solubility of EFX-Ca derived from a series of determined concentrations. The concentration of the working solution of EFX-Ca indicated by the UV-Vis spectrum was based on a $30 \times$ dilution on the saturated aqueous solution of EFX-Ca.

\subsection{In Vitro Antibacterial Activity Study}

The MIC and MBC values of EFX-Ca were further evaluated from in vitro antibacterial activity screening. Results of antibacterial data are listed in Table 2, which show that EFX and EFX-Ca exhibited similar antibacterial activities toward all five tested bacteria. The tested bacteria are common pathogens in humans, including Staphylococcus aureus, Escherichia coli, Salmonella typhi, Pseudomonas aeruginosa, and Proteus vulgaris.

Table 2. The antibacterial activity against five bacteria of EFX and EFX-Ca shown as MIC and MBC values $(\mu \mathrm{g} / \mathrm{mL})$.

\begin{tabular}{ccccc}
\hline \multirow{2}{*}{ Type of Bacteria } & \multicolumn{2}{c}{ EFX } & \multicolumn{2}{c}{ EFX-Ca } \\
\cline { 2 - 5 } & MIC & MBC & MIC & MBC \\
\hline S. aureus & 0.25 & 0.25 & 0.25 & 0.25 \\
E. coli & 0.0625 & 0.0625 & 0.03125 & 0.0625 \\
S. typhi & 0.03125 & 0.0625 & 0.03125 & 0.0625 \\
P. aeruginosa & 0.125 & 0.125 & 0.125 & 0.125 \\
P. vulgaris & 0.125 & 0.125 & 0.125 & 0.125 \\
\hline
\end{tabular}

Table 2 shows that EFX and its metal complexes for five pathogenic bacteria all had different degrees of bacteriostatic and bactericidal effects on bacteria. Among them, they 
had the best antibacterial effect against E. coli and $S$. typhi, followed by bactericidal action against $P$. aeruginosa and $P$. vulgaris, and the worst resistance to $S$. aureus. In addition, by comparing the ligands and complexes, it was evident that EFX and its metal complexes were quite similar to the MIC and MBC of five pathogenic bacteria with a slight change. This tiny change, however, indicated that the antibacterial effect of the EFX-Ca on E. coli was stronger than the ligand. EFX-Ca effectively retained the typical antibacterial activity of EFX after coordination with $\mathrm{Ca}(\mathrm{II})$, and appropriately improved the antibacterial ability against certain bacteria.

\subsection{In Vivo Acute Toxicity in Mice}

\subsubsection{Drug Effect on the Body Weight of Mice}

Based on the satisfying in vitro antibacterial activity of EFX-Ca indicated by the above MIC and MBC values, the in vivo tests for the biological activity of EFX-Ca were further carried out. In general, the acute toxicity test is the primary step in testing drug toxicity, and mice are the most commonly used target animals to assess this factor. So the acute toxicity of EFX-Ca, compared with EFX and EFX-Na, was firstly tested. The results of the influence on the body weight of mice under the treatment of EFX-Ca, EFX and EFX-Na, are listed in Tables 3, S2 and S3 (ESI†) as well as in Figures 3, S3 and S4 (ESI†). According to the results, except for the $16,000 \mathrm{mg} / \mathrm{kg}$, which could reduce the body weight of the mice on the first day (D1), the doses of EFX did not cause significant changes in body weight after administration, compared with the control group. In addition, at the end of the experimental observation period, the body weight of the mice was not significantly different from that of the control group. These results indicated that only high doses of EFX in aqueous solution affected the body weight of KM mice, and these effects were reversible over time. The results for the effect of EFX-Na on the body weight were comparable to those of EFX, but under much lower doses in the range of only 500-2000 mg/kg. Relative to the EFX results, EFX-Ca deeply affected the body weight of the mouse. Table 3 shows that the different doses of EFX-Ca caused the body weight of KM mice to decrease at the first day (D1) in groups 1-4 after administration. In addition, this trend of changes on the body weight had a certain relationship with the dosage of each dose group. The body weight for each group was enhanced again in a time-dependent mode. The effect of the EFX-Ca on the body weight of the tested mice was basically equal to that of EFX or EFX-Na. Thus, we concluded that the toxicity of EFX-Ca relative to its influence on body weight was as satisfying as that of EFX.

Table 3. Changes in the body weight $(\mathrm{g}, \bar{x} \pm \mathrm{SD})$ of the tested KM mice caused by EFX-Ca at different dosages $(2000,3031,4595,6964,10,556$ and $16,000 \mathrm{mg} / \mathrm{kg})$.

\begin{tabular}{ccccccc}
\hline \multirow{2}{*}{ Group } & $\begin{array}{c}\text { Dose } \\
(\mathbf{m g} / \mathbf{k g})\end{array}$ & \multicolumn{5}{c}{ Body Weight $(\mathbf{g}, \bar{x} \pm \mathbf{S D})$} \\
\cline { 3 - 7 } & & Day-0 & Day-1 & Day-4 & Day-7 & Day-14 \\
\hline Control & - & $17.21 \pm 1.25$ & $21.57 \pm 1.37$ & $27.03 \pm 1.53$ & $30.47 \pm 2.61$ & $35.00 \pm 5.19$ \\
1 & 16,000 & $17.84 \pm 1.23$ & $17.43 \pm 1.95 *$ & $23.55 \pm 2.66$ & $29.15 \pm 2.66$ & $37.25 \pm 4.57$ \\
2 & 10,556 & $17.67 \pm 0.72$ & $17.00 \pm 0.30 *$ & $21.53 \pm 2.10 *$ & $26.47 \pm 3.50 *$ & $34.00 \pm 7.50$ \\
3 & 6964 & $17.68 \pm 0.88$ & $17.21 \pm 1.22 *$ & $16.89 \pm 5.13 *$ & $23.11 \pm 4.21 *$ & $29.30 \pm 5.26 *$ \\
4 & 4595 & $17.31 \pm 1.05$ & $17.09 \pm 1.56 *$ & $20.10 \pm 5.55 *$ & $26.43 \pm 5.34 *$ & $33.60 \pm 7.07$ \\
5 & 3031 & $18.32 \pm 0.94$ & $19.61 \pm 1.23 *$ & $25.70 \pm 1.24$ & $28.44 \pm 2.14$ & $33.91 \pm 5.25$ \\
6 & 2000 & $17.51 \pm 1.14$ & $19.77 \pm 1.22 *$ & $25.91 \pm 1.83$ & $29.78 \pm 3.46$ & $33.33 \pm 5.64$ \\
\hline
\end{tabular}

Note: ${ }^{*} p<0.05$ (compared with control); The total number of the tested KM mice was 70. 


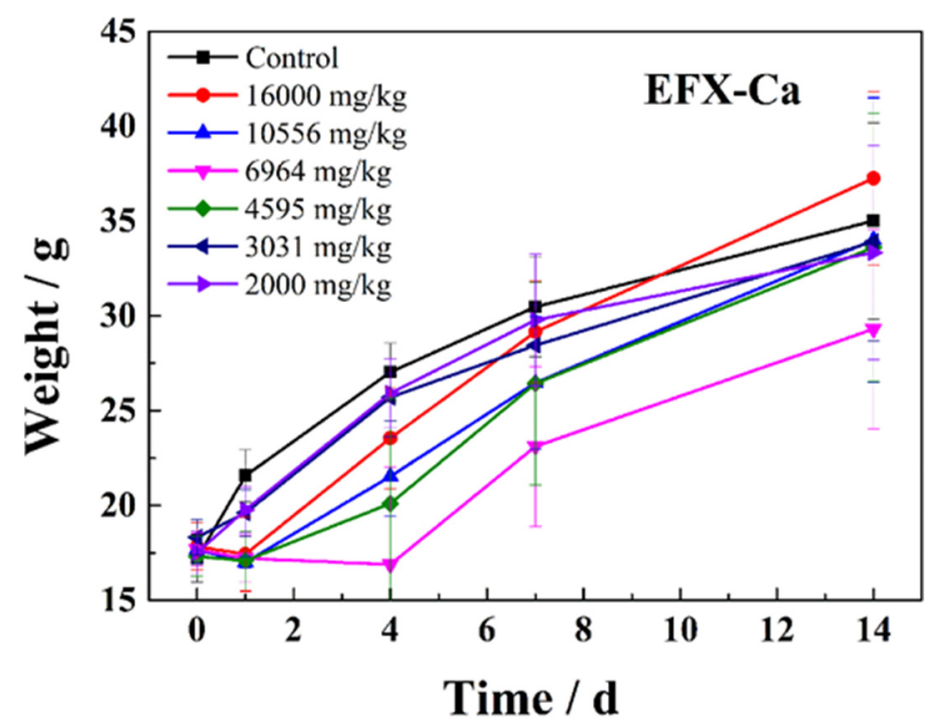

Figure 3. The time-dependent effects on the body weight of the tested KM mice after the oral administration of EFX-Ca at different dosages (2000, 3031, 4595, 6964, 10,556 and 16,000 mg/kg).

\subsubsection{Effect of Mice Mortality}

The relationship between the number of deaths in mice and the concentration of medication under the acute toxicity experiments is given in Table 4. Although EFX has been used as a common antibacterial drug for some time and has been tested for effectiveness and safety, we repeated the mortality test to determine a comparative role. We found that the number of surviving KM mice substantially increased when the dose of the drug was reduced, and the number of surviving KM mice in each dose group gradually reduced over time. Under the same dose, EFX-Ca showed significantly lower acute toxicity than EFX. This result clearly showed that under a dosage ranging from 2000 to $10,556 \mathrm{mg} / \mathrm{kg}$, the number of mouse deaths caused by the ligand was one or two more than the number of mouse deaths caused by the complex (out of 10). Note that the EFX-Ca did not cause death in mice at a concentration of $2000 \mathrm{mg} / \mathrm{kg}$, whereas the ligand caused the death of two mice at the same dosage.

According to the improved Karber's method, we calculated the $\mathrm{LD}_{50}$ value for EFX-Ca, EFX, and EFX-Na to be $7736 \mathrm{mg} / \mathrm{kg}, 5312 \mathrm{mg} / \mathrm{kg}$, and $1421 \mathrm{mg} / \mathrm{kg}$ with a $95 \%$ confidence interval of $5274.73-11,371.04 \mathrm{mg} / \mathrm{kg}, 3543.24-7954.26 \mathrm{mg} / \mathrm{kg}$, and $1136.84-1755.09 \mathrm{mg} / \mathrm{kg}$, respectively. This further proved that the coordination of calcium ions effectively reduced the toxicity of EFX. Thus, through the lethality, $\mathrm{LD}_{50}$, and the linear relationship between body weight and time after administration, we further verified that the tested complexes showed a significant reduction in acute toxicity in vivo compared with EFX alone.

Table 4. The acute toxicity test on KM mice administrated different dosages (2000, 3031, 4595, 6964, 10,556 and 16,000 mg/kg) of EFX-Ca, compared with EFX.

\begin{tabular}{lcccccc}
\hline \multicolumn{7}{c}{ EFX-Ca } \\
\hline Dose $(\mathrm{mg} / \mathrm{kg})$ & 2000 & 3031 & 4595 & 6964 & 10,556 & 16,000 \\
Death number & 0 & 3 & 4 & 3 & 7 & 10 \\
\hline & \multicolumn{7}{c}{ EFX } & & & \\
\hline Dose $(\mathrm{mg} / \mathrm{kg})$ & 2000 & 3031 & 4595 & 6964 & 10,556 & 16,000 \\
Death number & 2 & 5 & 5 & 4 & 9 & 10 \\
\hline
\end{tabular}

\subsection{Histopathological Examination}

On histopathological examination of the mice, there was no intra-abdominal fluid and the organs were in a normal position. Most organs, including the heart, liver, spleen, 
lung, kidney, large intestine, and small intestine, did not show changes in color, texture, or volume, which indicated a lack of obvious abnormalities and lesions. Subsequently, we compared histopathological observations of the tissue slices, as shown in Figure 4. Viewed from Figure $4 \mathrm{a}-\mathrm{g}$, respectively (for the heart, liver, spleen, lung, kidney, large intestine, and small intestine), in each high-dose group, the tissues and structures of the heart, liver, spleen, large intestine, and small intestine of the dead mice were basically normal, and the cells were stained uniformly, which indicated that the high-dose drug had no obvious toxic and side effects on these organs. In the high-dose group, EFX-Ca resulted in significant inflammatory cell infiltration of the lung tissue. EFX-Na caused more and larger glomeruli in kidney tissue, and EFX-Ca led to the enlargement of the renal capsule, which was accompanied by renal edema and lipid formation. This result suggested that the main target organ for the toxic side effects of EFX-Na was the kidney, whereas EFX-Ca had a slight effect on the kidney and lung.

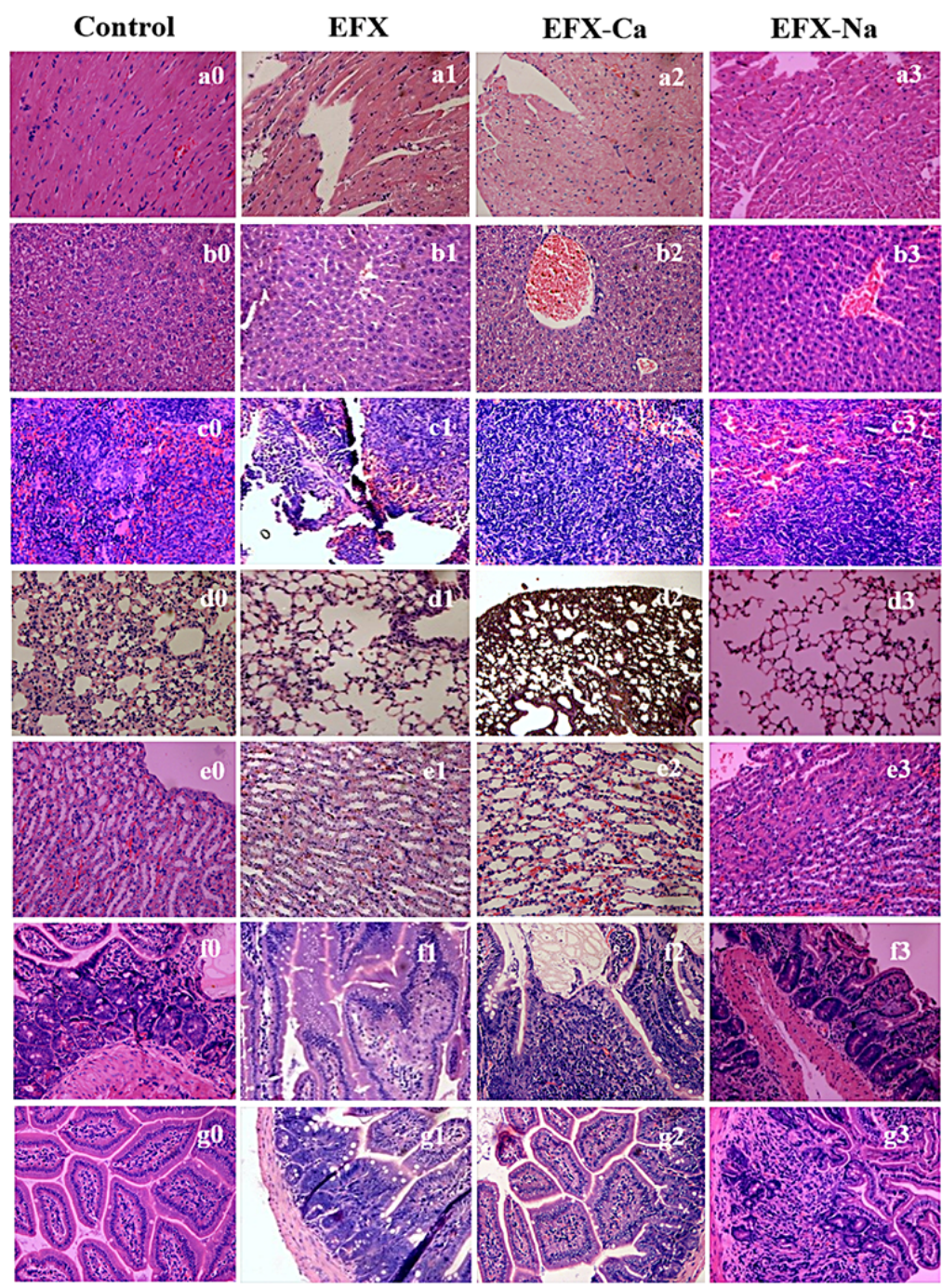

Figure 4. Histopathological images under $40 \times$ magnification on the main organs from the dead mice after the oral administration of EFX, EFX-Na, and EFX-Ca, in which the histologic tissue slices of (a) heart, (b) liver, (c) spleen, (d) lung, (e) kidney, (f) large intestine, and (g) small intestine were stained and visualized. Number 0, 1, 2, 3 indicates the effect of EFX, EFX-Ca and EFX-Na for each organ, respectively. 


\subsection{Pharmacokinetic Study on EFX-Ca}

It is necessary to study pharmacokinetics and pharmacodynamics (PK-PD) as one of the indexes to evaluate the medicinal properties of compounds. Therefore, PK-PD determination of EFX-Ca based on animal blood tests and analysis was further performed in rats, since the noninvasive blood collection in rats is more convenient than that in mice.

\subsubsection{Establishment of Standard Curve and the Minimum Concentration for} Administration

In the range of drug concentration from 0.05 to $1.0 \mu \mathrm{g} / \mathrm{mL}$, the chromatographic peak area had a good linear relationship with the concentration of each standard working solution $\left(R^{2}=0.9997\right)$, and we obtained the linear curve of the standard curve as $y=19,373 x-72.512$. In addition, the lowest concentration that we detected was $0.025 \mu \mathrm{g} / \mathrm{mL}$. Table S4 and Figure S5 (ESIt) provide the details.

\subsubsection{Pharmacokinetic Analysis}

The plasma samples collected at different time points for the pharmacokinetic properties of EFX-Ca compared with EFX were examined and analyzed accordingly. According to the specification curve, we could record the peak areas and all of the plasma concentrations at different time points, through which the average drug-time curve could be drawn (as shown in Figure 5). The drug concentrations in the plasma of SD rats for EFX-Ca and EFX at different time points after administration are given in Table S5 (ESI + ). By means of data manipulation and analysis in silico, we obtained a series of primary pharmacokinetic parameters (as listed in Table 5).

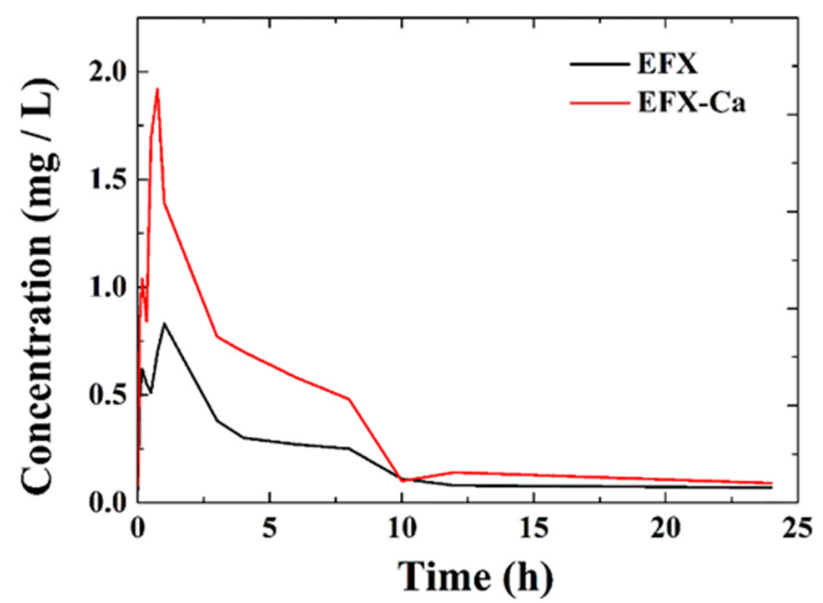

Figure 5. The relationship between drug concentration and the elimination time in plasma samples from the tested SD rats treated with EFX-Ca and EFX at different time points $(0,0.083,0.333,0.5,0.75$, $1,3,4,6,8,10,12$, and $24 \mathrm{~h}$ ).

Table 5. Main pharmacokinetic parameters of the plasma sample from the tested SD rats under the oral administration of EFX and EFX-Ca, respectively.

\begin{tabular}{cccc}
\hline Parameter & Unit & EFX (10 $\mathbf{~ g / / k g )}$ & EFX-Ca (12 $\mathbf{~ m g / k g )}$ \\
\hline$C_{\max }$ & $\mathrm{ng} / \mathrm{mL}$ & 830 & 1920 \\
$T_{\max }$ & $\mathrm{H}$ & 1 & 0.75 \\
$t_{1 / 2 \beta}$ & $\mathrm{H}$ & 2.43 & 4.41 \\
$\mathrm{AUC}_{0-\mathrm{t}}$ & $\mathrm{ng} \cdot \mathrm{h} / \mathrm{mL}$ & 2702.50 & 5875.83 \\
$\mathrm{Ke}$ & - & 0.28 & 0.16 \\
$\mathrm{Vd}$ & $\mathrm{mL} / \mathrm{kg}$ & 1053.16 & 267.44 \\
$\mathrm{Cl}$ & $\mathrm{mL} / \mathrm{kg} \cdot \mathrm{h}$ & 37.00 & 20.42 \\
\hline
\end{tabular}


As shown in Table 5, we calculated the apparent volume of distribution Vd to be $1053.16 \mathrm{~mL} / \mathrm{kg}$, after we orally administered EFX $(10 \mathrm{mg} / \mathrm{kg})$ to SD rats. The highest plasma concentration was $830 \mathrm{ng} / \mathrm{mL}$, the peak time was $1 \mathrm{~h}$, the half-life of elimination was $2.43 \mathrm{~h}$, and the area under the drug-time curve (AUC) was $2702.50 \mathrm{ng} \cdot \mathrm{h} / \mathrm{mL}$, with a clearance rate of $37 \mathrm{~mL} / \mathrm{kg} \cdot \mathrm{h}$. These parameters indicated that EFX could be rapidly and widely distributed and eliminated slowly in SD rats. Comparatively, under the same experimental conditions, after we orally administered EFX-Ca (12 mg/kg) to SD rats, the apparent volume of distribution $\mathrm{Vd}$ was $267.44 \mathrm{~mL} / \mathrm{kg}$, the highest plasma concentration was $1920 \mathrm{ng} / \mathrm{mL}$, the peak time was $1 \mathrm{~h}$, the half-life of elimination was $4.41 \mathrm{~h}$, and the AUC was $5875.83 \mathrm{ng} \cdot \mathrm{h} / \mathrm{mL}$, with a clearance rate of $20.42 \mathrm{~mL} / \mathrm{kg} \cdot \mathrm{h}$. We also found that EFX-Ca could be rapidly and widely distributed and slowly eliminated in SD rats.

After oral administration of the same effective dose of the drug in SD rats, the parameters not only indicated that the long half-life and the widely rapidly distributed metabolic characteristics were the same, but also showed the difference between EFX and EFX-Ca by comparing the main pharmacokinetic parameters. To a certain extent, the pharmacokinetic characteristics of EFX were different from EFX-Ca. The AUC of EFX-Ca was $5875.83 \mathrm{ng} \cdot \mathrm{h} / \mathrm{mL}$, which was more than twice that of EFX $(2702.50 \mathrm{ng} \cdot \mathrm{h} / \mathrm{mL})$. The results also demonstrated that the coordination of EFX with $\mathrm{Ca}$ (II) could increase the total amount of drug into the systemic circulation. In addition, the highest plasma concentration of EFX was $830 \mathrm{ng} / \mathrm{mL}$, which was lower than that of EFX-Ca $(1920 \mathrm{ng} / \mathrm{mL})$, but its peak time $(1 \mathrm{~h})$ was higher than EFX-Ca $(0.75 \mathrm{~h})$. This result indicated that the binding rate of EFX to plasma protein in rats was higher than the EFX-Ca, but it naturally reduced its bioavailability in animals. The production of its calcium complex effectively alleviated this situation. Furthermore, the half-life of elimination of EFX was tested to be $2.43 \mathrm{~h}$, which was lower than that of EFX-Ca. Therefore, this result indicated that EFX could prolong the drug effect after coordinating with the bioactive calcium(II), and finally, it could improve drug utilization.

\subsection{In Vivo Acute Toxicity and Anti-Inflammatory Effects on Zebrafish}

As a small tropical freshwater fish, zebrafish has the characteristics and advantages of high homology with mammals, short development and growth cycle, autotrophic development within one week, etc. [33]. As a result, zebrafish have been developed into a mature and efficient drug screening platform [34,35]. In order to more comprehensively study the potential toxicity and anti-inflammatory effects of EFX-Ca, the zebrafish system and its two typical inflammatory models respectively induced by $\mathrm{CuSO}_{4}$ and $\mathrm{H}_{2} \mathrm{O}_{2}$ were also used to compare the toxicological properties between EFX-Ca and EFX.

\subsubsection{The In Vivo Acute Toxicity in Zebrafish}

The acute toxicity of EFX-Ca, compared with EFX and EFX-Na [36], was primarily tested in the zebrafish incubation system, from which the developmental status or the potential physiological abnormalities of the zebrafish, treated by medicated bath of different dosage of EFX-Ca and EFX, respectively, were monitored and examined to provide greater understanding and insight into the potential alteration on the toxicity of the $\mathrm{Ca}$ (II)-based enrofloxacin in vivo.

A concentration range from 0.01 to $20 \mu \mathrm{M}$ and an incubation time range from 24 to $120 \mathrm{hpf}$ were adopted to give a more legible assessment for the tested compounds [36]. The experimental results are shown in Figures S6 and S7 (ESIt), in which the zebrafish showed no obvious physiological abnormalities under the incubation with the full-range concentration of EFX-Ca. However, the embryonic development rate of zebrafish decreased gradually in a dose-dependent manner, while the body length of zebrafish was also slightly affected after the medicated bath compared to our previously reported copper(II) complex of enrofloxacin, EFX-Cu [36]. The acute toxicity of EFX-Ca, as well as EFX, to the zebrafish embryos and larvae was significantly reduced at the same concentration, suggesting a much lower acute cytotoxicity of this $\mathrm{Ca}$ (II)-based enrofloxacin. On the other hand, similar to 
EFX-Na [36], when EFX-Ca or EFX were given at a higher concentration, the fetal membrane of the zebrafish embryos sometimes appeared villous or flocculent. The statistical data of survival and death of zebrafish after incubation with different concentrations of EFX-Ca or EFX are shown in Table 6.

Table 6. The statistical survival (death) of the tested zebrafish under the medicated bath of different concentrations $(0.01,0.1,1,10,20 \mu \mathrm{M})$ of EFX-Ca or EFX.

\begin{tabular}{|c|c|c|c|c|c|c|}
\hline & \multicolumn{6}{|c|}{ EFX-Ca } \\
\hline & Control & 0.01 & 0.1 & 1 & 10 & 20 \\
\hline $24 \mathrm{hpf}$ & $28(2)$ & $24(6)$ & $26(4)$ & $28(2)$ & $26(4)$ & $30(0)$ \\
\hline $48 \mathrm{hpf}$ & $28(2)$ & $24(6)$ & $26(4)$ & $28(2)$ & $26(4)$ & $30(0)$ \\
\hline $72 \mathrm{hpf}$ & $28(2)$ & $24(6)$ & $26(4)$ & $28(2)$ & $26(4)$ & $30(0)$ \\
\hline $96 \mathrm{hpf}$ & $28(2)$ & $22(8)$ & $26(4)$ & $28(2)$ & $26(4)$ & $30(0)$ \\
\hline \multirow[t]{3}{*}{$120 \mathrm{hpf}$} & $28(2)$ & $22(8)$ & $26(4)$ & $28(2)$ & $26(4)$ & $30(0)$ \\
\hline & \multicolumn{6}{|c|}{ EFX } \\
\hline & Control & 0.01 & 0.1 & 1 & 10 & 20 \\
\hline $24 \mathrm{hpf}$ & $28(2)$ & $24(6)$ & $26(4)$ & $28(2)$ & $28(2)$ & $26(4)$ \\
\hline $48 \mathrm{hpf}$ & $28(2)$ & $24(6)$ & $26(4)$ & $28(2)$ & $28(2)$ & $26(4)$ \\
\hline $72 \mathrm{hpf}$ & $28(2)$ & $24(6)$ & $26(4)$ & $28(2)$ & $28(2)$ & $26(4)$ \\
\hline $96 \mathrm{hpf}$ & $28(2)$ & $24(6)$ & $26(4)$ & $28(2)$ & $28(2)$ & $26(4)$ \\
\hline $120 \mathrm{hpf}$ & $28(2)$ & $24(6)$ & $26(4)$ & $28(2)$ & $28(2)$ & $26(4)$ \\
\hline
\end{tabular}

\subsubsection{The In Vivo Anti-Inflammatory Effects Induced by $\mathrm{CuSO}_{4}$ in $\mathrm{Zebrafish}$}

With the transgenic $\operatorname{Tg}(\mathrm{mpx}$ :eGFP) zebrafish as the research object, the process of inflammatory cell aggregation and migration in zebrafish can be easily observed in a noninvasive real-time dynamic manner, especially through this type of transparent juvenile zebrafish, so as to compare the anti-inflammatory effects of EFX-Ca and EFX.

Firstly, by using the GFP-labeling method to observe the zebrafish in the control group, it was found that neutrophils were evenly distributed in the body of zebrafish, and did not gather in clusters, as shown in Figure 6 [37-39]. On the contrary, in the tested zebrafish induced by $\mathrm{CuSO}_{4}$, neutrophils were obviously observed to migrate and eventually cluster together [37-39]. After pre-incubation with EFX-Ca or EFX at different concentrations for $1 \mathrm{~h}$, the tested zebrafish showed varying degrees of resistance to $\mathrm{CuSO}_{4}$-induced neutrophil aggregation. Although the aggregation of neutrophils could not be completely inhibited at lower concentrations, there was a certain difference between EFX-Ca and EFX with the increasing concentrations of the medicated bath. For EFX, partial aggregations of the neutrophils could be observed in zebrafish even after the pretreatment at the maximum concentration of $1 \mu \mathrm{M}$. Under the same concentration of EFX-Ca, the neutrophil aggregation was more effectively inhibited. Especially in the presence of EFX-Ca at a lower concentration of $0.1 \mu \mathrm{M}$, neutrophils in zebrafish could be observed to be significantly dispersed, while neutrophils of the EFX-treated group under the same concentration still maintained obvious clustering status, indicating that EFX-Ca has a stronger anti-inflammatory effect on $\mathrm{CuSO}_{4}$ induced zebrafish than EFX, with a certain concentration-dependence. It should be noted that 10-15 zebrafish were set and treated in each group, and three of them were chosen randomly for examination for each group. Only one of the three zebrafish in each group is shown in Figure 6, so that the results could be demonstrated more characteristically. While the other two examined zebrafish with similar results in each group were compared and are together shown in Figures S8 and S9 (ESIt). The following anti-inflammatory results for the $\mathrm{H}_{2} \mathrm{O}_{2}$-induced zebrafish were also shown in this manner, respectively in Figures 7, S10 and S11 (ESIt). 


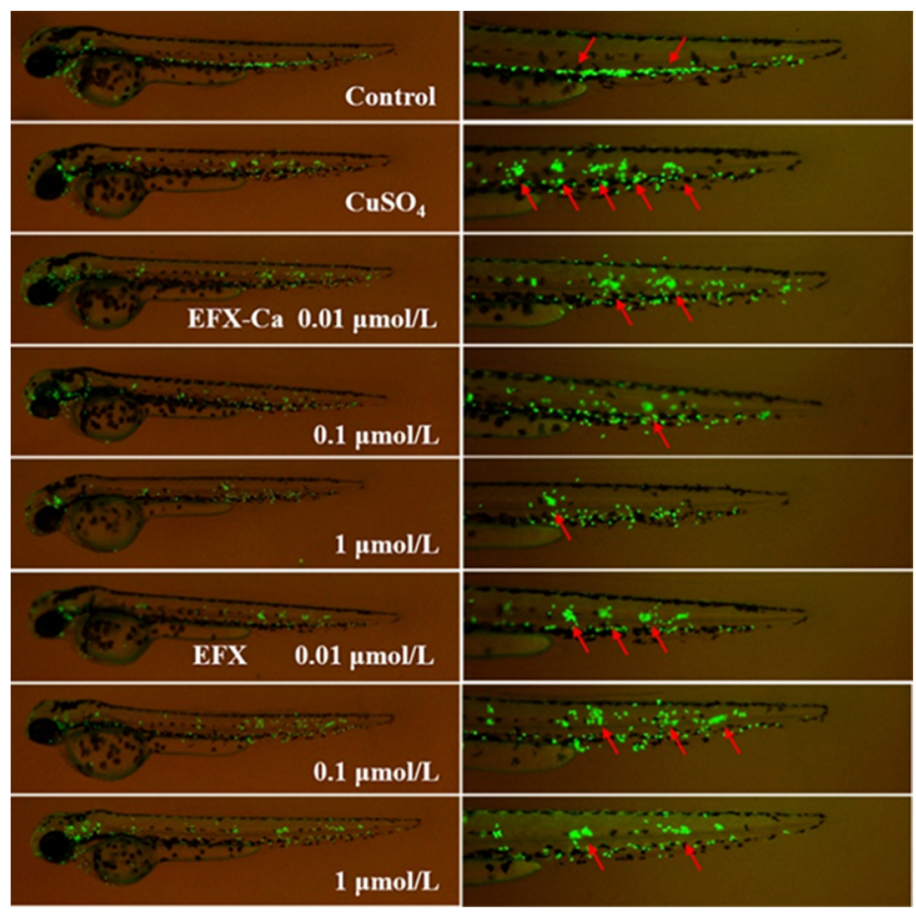

Figure 6. The inhibition effect of EFX-Ca, compared with EFX at the same concentrations (0.01, $0.1,1 \mu \mathrm{M})$, on the observed neutrophil cluster aggregation under the $\mathrm{CuSO}_{4}$-induced mode of the transgenic zebrafish line $\operatorname{Tg}(\mathrm{mpx}$ :eGFP). The partial magnified images of the latter part of the zebrafish were shown on the right side. The red arrows in the right side represent aggregations of neutrophils.

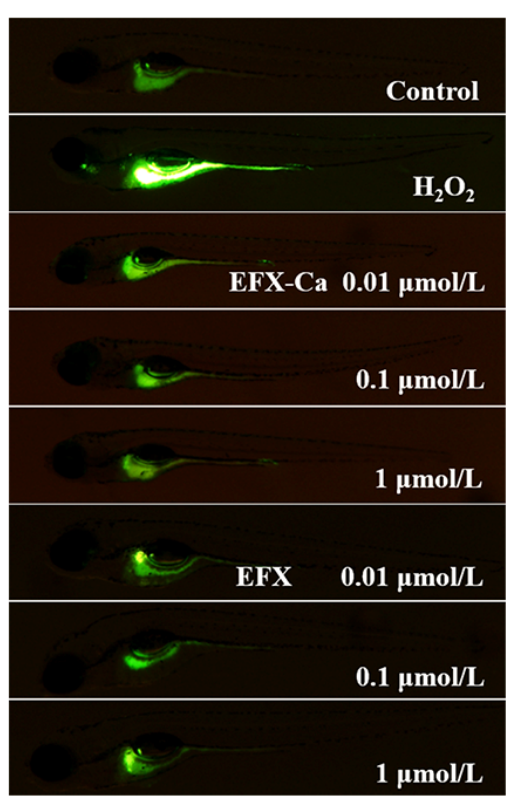

(A)

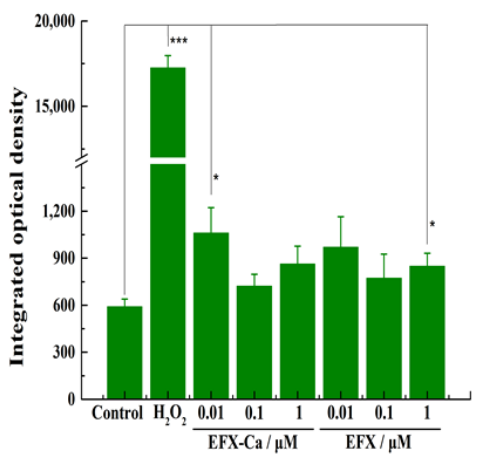

(B)

Figure 7. (A) The anti-inflammatory effect of EFX-Ca, compared with EFX at the same concentrations $(0.01,0.1,1 \mu \mathrm{M})$, on the $\mathrm{H}_{2} \mathrm{O}_{2}$-induced ROS production in zebrafish model, indicated by the green fluorescence probe and visualized by the added DCFH-DA. (B) The quantitative results for the oxidative stress in zebrafish, represented by the histogram on the right side, were statistically analyzed based on examining the integrated optical density (IOD) of the green fluorescence in the tested zebrafish. Mean \pm SD: ${ }^{*} p<0.05,{ }^{* * *} p<0.001$. 


\subsubsection{The In Vivo Anti-Inflammation Effects Induced by $\mathrm{H}_{2} \mathrm{O}_{2}$ in Zebrafish}

According to the above results based on the $\mathrm{CuSO}_{4}$-induced inflammation model in zebrafish, EFX-Ca and EFX both showed anti-inflammatory effects to varying degrees. In the early stage of inflammation, oxidative stress in the injured site was activated and a large amount of ROS was released. Therefore, in order to further confirm whether EFX-Ca could exhibit the antioxidant effect, $\mathrm{H}_{2} \mathrm{O}_{2}$ was also selected to induce oxidative stress in zebrafish, and the green fluorescent probe (DCFH-DA) was used for the visual detection [36]. The experimental results are shown in Figure 7, Figures S10 and S11 (ESIt).

By comparing the blank group with the $\mathrm{H}_{2} \mathrm{O}_{2}$-induced oxidative stress group, it can be seen that after the addition of DCFH-DA probe, the green fluorescence in the $\mathrm{H}_{2} \mathrm{O}_{2}$ induced group was significantly enhanced, compared with the blank group, indicating that the zebrafish had produced an obvious oxidative stress reaction in vivo. However, when comparing the zebrafish that received the same $\mathrm{H}_{2} \mathrm{O}_{2}$ stimulation with and without the $48 \mathrm{~h}$ of pre-treatment with the medicated bath (EFX-Ca or EFX), the green fluorescence was significantly weaker than that of the positive group induced by $\mathrm{H}_{2} \mathrm{O}_{2}$ (with the average IOD (Integrated Optical Density) $=17,250$ a.u.). Especially in the 1 and $0.1 \mu \mathrm{M}$ medicated bath groups, the green fluorescence was very weak, with corresponding average IODs of 863 and 721 for EFX-Ca, and 848 and 772 for EFX, respectively, which was basically very close to that in the un-induced control group (average IOD $=590$ ), indicating that both EFX-Ca and EFX could effectively resist the production of ROS in zebrafish when stimulated by $\mathrm{H}_{2} \mathrm{O}_{2}$. Even at the lowest concentration $(0.01 \mu \mathrm{M})$ of EFX-Ca or EFX, the green fluorescence was also greatly reduced to the average IOD of 1060 for EFX-Ca and 970 for EFX, respectively. All of the average IOD \pm SD values for statistical analysis are summarized in Table S6. In conclusion, both EFX-Ca and EFX can effectively resist or remove the $\mathrm{H}_{2} \mathrm{O}_{2}$-induced $\mathrm{ROS}$ production, and they also show an overall concentration dependence. Comparatively, EFX-Ca has a slightly stronger anti-ROS production ability than EFX, which could be proved from the results of all three concentration groups. This result is consistent with the results of the $\mathrm{CuSO}_{4}$-induced inflammation model in zebrafish.

Overall, the above experimental results based on the zebrafish platform have clearly indicated that EFX-Ca showed satisfying anti-inflammatory activity in vivo, and the antiinflammatory effect is slightly better than EFX, which will be an important basis for the development of EFX-Ca as a potential metal-based veterinary drug, and will also provide a mechanism for the following in vivo experiments of bacterial infection-treatment evaluation. On the other hand, EFX-Ca and the original drug, EFX, showed similar in vivo toxicity in zebrafish, which was different from the distinguishing acute toxicity between EFX-Ca and EFX evaluated in mice. However, both of the different in vivo acute toxicity assessments showed that the toxicity of EFX-Ca was not higher than that of enrofloxacin and had ideal drug safety.

\subsection{Quasi-Clinical Trial on Two Types of Infected Broilers}

EFX is one of the most commonly used therapeutic drugs in the veterinary drug market. It has the characteristics of broad spectrum antibacterial activity, significant efficacy and low price [12-14]. EFX-Ca, as a potential alternative to EFX, has also been proven to maintain broad spectrum antibacterial activity while keeping the same cost, especially for G-type bacteria, such as E. coli, so it is indeed necessary to evaluate whether the efficacy of EFX can be achieved or even higher in the animal clinic. Therefore, we further investigated the therapeutic effect of EFX-Ca on bacterial infection in chickens, which are commonly used for EFX treatment.

\subsubsection{General Clinical Observations on the Infected Chickens}

The mental state, food intake, water intake, and excretion of feces were normal in the healthy control group that was not infected and not given the drug. In each administration group, a certain number of chickens died in the first two days after administration, accompanied by different degrees of depression and lethargy, a sharp decline in food intake, and 
increased water intake. Additionally, these chickens occasionally issued a hoarse "gurgling" sound and exhibited other clinical symptoms. Compared with the uninfected chickens that showed normal symptoms and excreted normal feces (Figure S12A,B), most of the infected chickens appeared isolated, motionless, or gathered and curled up in a corner, with eyes closed or half open and dozing, head buried under wings, wings drooping, unkempt feathers, and other symptoms (see Figure S12C). The chickens that were administered EFX-Ca also excreted loose feces, which were mostly green, yellow-green, or in white liquid, and sometimes had blood stool or egg-white-like feces, and the feathers near the anus were often contaminated with feces (Figure S12D,E). Some chickens were severely dehydrated because of the diarrhea caused by pathogenic bacteria and inadequate drinking (Figure S12F). On day 3 following the administration of each dose group, the mental state of some chickens improved significantly, and they could walk freely and began to eat and drink freely. The feces changed from thin to soft, from yellow-green egg-white to gray-black column or lump, and a small amount of white urate could also be found. The intake of chickens began to increase, and the number of deaths of chickens gradually decreased. On days 4-5 following the administration of the drug, a small number of infected chickens still died, and some of the chickens curled up, were depressed, and excreted yellow-green loose feces. By day 6 following administration, most of the chickens were able to return to a normal state.

We observed the pathologic anatomy of the tested chickens in the healthy control group (not infected, not given) and compared this with those that died in the infected group without drug administration. We found that the diseased chickens that died showed marked symptoms of perihepatic inflammation, pericarditis, balloon inflammation, omphalitis, ophthalmitis, articular synovitis, hemorrhagic enteritis, and granuloma, as well as dehydration resulting from diarrhea. Detailed autopsy of some tissues and organs are shown in Figure S13.

\subsubsection{The In Vivo Therapeutic Effect on the Infected Chickens after Drug-Mixed Feeding}

We conducted quasi-clinical trials to examine the therapeutic effects of both EFX and EFX-Ca on the broilers infected by E. coli. EFX and EFX-Ca at high, medium, and low doses for two types of regular broilers (AA white feather broiler chickens (AA) and 817 mixed broiler chickens (817)) infected with E. coli were analyzed and compared. As shown in Tables 7 and 8, the experimental results showed that under the same feeding conditions (temperature, light, and ventilation), a single dose of EFX and different doses of EFX-Ca had significant therapeutic effects on AA white feather broiler chickens and 817 broiler chickens (with stronger disease resistance) that were infected with E. coli and the therapeutic effects varied with different drugs and doses. For the AA white feather broiler, the therapeutic effect of different doses was as follows: EFX-Ca (medium dose) $>$ EFX $>$ EFX-Ca (high dose) $>$ EFX-Ca (low dose), with the corresponding cure rates of 78\%, 62\%, 60\%, and 54\%, respectively. For the infected 817 broiler chickens, the therapeutic effects of each dose group were as follows: EFX-Ca (low dose) > EFX-Ca (medium dose) > EFX > EFX-Ca (high dose), with the corresponding cure rates of $88 \%, 80 \%, 64 \%$, and $58 \%$, respectively.

In general, the efficacy of EFX-Ca in the medium- and low-dose groups was higher than that of EFX in chickens infected with E. coli, indicating that EFX-Ca was a more appropriate therapeutic concentration as a potential veterinary drug. Under these two doses, EFX-Ca had the highest cure rate for AA and 817 infected chickens, which were $25.8 \%$ and $37.5 \%$ higher than the EFX dose group, respectively. When the high-dose EFX-Ca reacted quickly with chickens infected with $E$. coli, however, the mortality rate of chickens was relatively high. We speculated that the high-dose EFX-Ca ruptured the bacteria and released a large amount of endotoxin, further leading to the increased mortality of the chickens [40-44]. For these two different types of chickens, the optimal dosage of EFX-Ca was different, and too high or too low concentration was not conducive to the therapeutic effect of infected chickens. This should be given special attention and treated differently in subsequent administration of clinical medication trials. 
Table 7. The survival numbers, cure rates, and relative weight gain rates on two typical broilers after drug-mixed feeding of EFX and different dosages of EFX-Ca, respectively.

\begin{tabular}{|c|c|c|c|c|c|c|}
\hline $\begin{array}{l}\text { Type of } \\
\text { Broilers }\end{array}$ & Group & Number & $\begin{array}{l}\text { Survival } \\
\text { Number }\end{array}$ & Cure Rate (\%) & $\begin{array}{c}\text { Average Weight } \\
\text { Gain }\end{array}$ & $\begin{array}{c}\text { Relative Weight } \\
\text { Gain Rate (\%) }\end{array}$ \\
\hline \multirow{5}{*}{ AA } & Control & 50 & 50 & 100 & 730 & 100 \\
\hline & EFX & 50 & 31 & 62 & 380 & 52 \\
\hline & EFX-Ca (High) & 50 & 30 & 60 & 250 & 34 \\
\hline & EFX-Ca (Medium) & 50 & 39 & 78 & 140 & 19 \\
\hline & EFX-Ca (Low) & 50 & 27 & 54 & 190 & 26 \\
\hline \multirow{5}{*}{817} & Control & 50 & 50 & 100 & 600 & 100 \\
\hline & EFX & 50 & 32 & 64 & 100 & 17 \\
\hline & EFX-Ca (High) & 50 & 29 & 58 & 70 & 12 \\
\hline & EFX-Ca (Medium) & 50 & 40 & 80 & 80 & 13 \\
\hline & EFX-Ca (Low) & 50 & 44 & 88 & 280 & 47 \\
\hline
\end{tabular}

Note: Relative weight gain rate $=$ (the average weight gain per dose/weight gain in the healthy control group) $\times 100 \%$.

Table 8. The influence on the body weight, feed consumption and feed conversion ratios on two typical broilers after drug-mixed feeding of EFX and different dosage of EFX-Ca, respectively.

\begin{tabular}{|c|c|c|c|c|c|c|c|}
\hline $\begin{array}{l}\text { Type of } \\
\text { Broilers }\end{array}$ & Group & $\begin{array}{l}\text { Average Initial } \\
\text { Weight (g) }\end{array}$ & $\begin{array}{l}\text { Average Final } \\
\text { Weight (g) }\end{array}$ & $\begin{array}{c}\text { Average } \\
\text { Increment of } \\
\text { Weight (g) }\end{array}$ & $\begin{array}{c}\text { Total Feed } \\
\text { Consumption (g) }\end{array}$ & $\begin{array}{c}\text { Average Feed } \\
\text { Consumption (g) }\end{array}$ & $\begin{array}{c}\text { Feed } \\
\text { Conversion } \\
\text { Ratio (FCR) }\end{array}$ \\
\hline \multirow{5}{*}{ AA } & Control & $1500 \pm 68$ & $2230 \pm 104$ & 730 & 67,000 & 1340 & $1.84: 1$ \\
\hline & EFX & $1630 \pm 120$ & $1880 \pm 113$ & 250 & 13,200 & 264 & $1.06: 1$ \\
\hline & EFX-Ca (High) & $1520 \pm 78$ & $1750 \pm 125$ & 230 & 15,000 & 300 & $1.30: 1$ \\
\hline & EFX-Ca (Medium) & $1360 \pm 57$ & $1640 \pm 73$ & 280 & 16,000 & 320 & $1.14: 1$ \\
\hline & EFX-Ca (Low) & $1500 \pm 94$ & $1690 \pm 95$ & 190 & 11,000 & 220 & $1.16: 1$ \\
\hline \multirow{5}{*}{817} & Control & $930 \pm 71$ & $1530 \pm 74$ & 600 & 51,000 & 1020 & $1.7: 1$ \\
\hline & EFX & $890 \pm 56$ & $1030 \pm 74$ & 140 & 7300 & 146 & $1.04: 1$ \\
\hline & EFX-Ca (High) & $920 \pm 58$ & $1000 \pm 51$ & 80 & 4500 & 90 & $1.13: 1$ \\
\hline & EFX-Ca (Medium) & $870 \pm 47$ & $1010 \pm 61$ & 140 & 7500 & 150 & $1.07: 1$ \\
\hline & EFX-Ca (Low) & $950 \pm 56$ & $1210 \pm 67$ & 260 & 14,000 & 280 & $1.08: 1$ \\
\hline
\end{tabular}

\section{Materials and Methods}

\subsection{Reagents and Instruments}

All of the chemical reagents were of analytical grade and were commercially available. Anhydrous dextrose was purchased from Xi'wang Pharmaceutical Co., Ltd. (Zouping, China). We used all reagents without further purification. We purchased enrofloxacin (EFX) from Hangzhou Mei'bo Pharmaceutical Chemical Co., Ltd. (Hangzhou, China), $\mathrm{Ca}\left(\mathrm{NO}_{3}\right)_{2} \cdot 4 \mathrm{H}_{2} \mathrm{O}$ from Alfa Aesar, and $10 \%$ formalin from Beijing Solarbio Science \& Technology Co., Ltd. (Beijing, China). The standard EFX as a reference was purchased from the China Veterinary Drug Supervision Institute. All the tested mice and rats were obtained from the animal experimental center of Guangxi Medical University. Five hundred 4-week-old broilers in two types (AA white feather broilers (AA) and 817 hybrid broilers (817)) were purchased from Kang'da Livestock and Poultry Co., Ltd. (Langfang, China). All experiments were performed in compliance with the policy on animal use and ethics of Guangxi Medical University, and the animals' blood or organs were taken under anesthesia, with quiet, rapid and painless death. To be specific, both the mice and rats used in this experiment were killed by spinal dislocation and the broilers were killed by cutting the carotid artery behind the ear with a scalpel.

The EFX-Ca and EFX were dissolved in DMSO to prepare the stock solution at a concentration of $0.67 \mathrm{mM}$. We prepared tris- $\mathrm{NaCl}$ buffer solution $(5 \mathrm{mM}$ Tris, $50 \mathrm{mM} \mathrm{NaCl}$, adjusted to $\mathrm{pH}=7.3$ by hydrochloric acid), $0.9 \%$ normal saline, bouillon culture-medium, and solid medium using double-distilled water. The solutions were all sterilized for $30 \mathrm{~min}$ at $121{ }^{\circ} \mathrm{C}$ before being stored in the refrigerator. A series of concentrations $(50,76,115,174$, 264, and $400 \mathrm{mg} / \mathrm{mL}$ ) of EFX-Ca and EFX were prepared by diluting the respective stock solutions with distilled water. The infrared (IR) spectra were obtained on a PerkinElmer Fourier transform-IR (FT-IR) Spectrometer. Elemental analyses (C, H, and N) were carried out on a PerkinElmer Series II CHNS/O 2400 elemental analyzer. The mass spectra were 
recorded on a Thermo-Finngan LCQ/AD Quadrupole Ion Trap electrospray ionizationmass spectrometer (ESI-MS). The analysis on the stability of the complex in solution was performed on an ANL404 PerkinElmer ultraviolet-visible (UV-Vis) spectrometer and the pharmacokinetic characteristics were obtained on an Agilent 1200-6410 HPLC/MS system.

\subsection{Synthesis of $\left[\mathrm{Ca}(\mathrm{EFX})_{2}\left(\mathrm{H}_{2} \mathrm{O}\right)_{4}\right] \cdot \mathrm{H}_{2} \mathrm{O}(\mathrm{EFX}-\mathrm{Ca})$}

EFX (0.1 mmol, $0.0360 \mathrm{~g})$ was dissolved in $7 \mathrm{~mL}$ acetone and $8 \mathrm{~mL}$ water and adjusted to $\mathrm{pH} 7.5$ by addition of triethylamine, yielding a clear yellow solution. $\mathrm{Ca}\left(\mathrm{NO}_{3}\right)_{2} \cdot 4 \mathrm{H}_{2} \mathrm{O}$ $(0.05 \mathrm{mmol}, 0.0120 \mathrm{~g})$ dissolved in $10 \mathrm{~mL}$ water was added dropwise to this solution. The mixed solution was refluxed and stirred at $65^{\circ} \mathrm{C}$ for $10 \mathrm{~h} \mathrm{[32].} \mathrm{The} \mathrm{obtained} \mathrm{colorless} \mathrm{and}$ transparent resultant was filtered, allowed to stand overnight, and then allowed to slowly evaporate for several days, before the EFX-Ca precipitated into colorless and transparent crystals, from which we selected single crystals for the single X-ray crystal diffraction analysis. Then, we filtered the product again and washed it twice with anhydrous ethanol before it was dried in vacuo overnight (Yield: 75\%). FT-IR $\left(\mathrm{KBr}, \mathrm{cm}^{-1}\right): 3410.06(\mathrm{~m}, v \mathrm{O}-\mathrm{H})$, $2811.69(\mathrm{~m}, v \mathrm{Ar}-\mathrm{H}), 2966.29(\mathrm{~m}, v \mathrm{~N}-\mathrm{H}),(\mathrm{C}=\mathrm{O}) 1576.97(\mathrm{vs}, v \mathrm{C}=\mathrm{O}), 1623.96$ (vs, vO-C=O, asym), $1391.02\left(\mathrm{~m}, v \mathrm{O}-\mathrm{C}=\mathrm{O}\right.$, sym), and 1486.59 (s, vC=C). Calc. for $\mathrm{C}_{38} \mathrm{H}_{52} \mathrm{CaF}_{2} \mathrm{~N}_{6} \mathrm{O}_{11}$ $(\mathrm{Mw}=846.93)$ : C 53.84, H 6.14, N 9.92; Found. C 53.25, H 6.04, N 9.85\%. ESI-MS: $m / z 360.3$ $[\mathrm{EFX}+\mathrm{H}]^{+}, 719.4[2 \mathrm{EFX}+\mathrm{H}]^{+}, 554.2[\mathrm{EFX}+\mathrm{Ca}+2 \mathrm{DMSO}-\mathrm{H}]^{+}, 757.3[2 \mathrm{EFX}+\mathrm{Ca}-\mathrm{H}]^{+}$ (ESI†, Figures S14 and S15).

\subsection{X-ray Crystallography}

We collected single X-ray crystal diffraction data for EFX-Ca and EFX on a Bruker APEX-II CCD diffractometer equipped with graphite monochromated Mo-K $\alpha$ radiation $(\lambda=0.07107 \mathrm{~nm})$ at room temperature. We solved the structure and refined it according to direct methods, using OLEX2 and SHELXL-97 programs [45]. We added the hydrogen atoms theoretically, riding on the concerned atoms. The crystallographic data and refinement details of the structure analyses are summarized in Tables 1 and S1.

\subsection{Determination on the Water Solubility of EFX-Ca}

We determined the water solubility of EFX-Ca and EFX for comparison by means of UV-Vis spectroscopy, in which we monitored the maximum absorbance at $291 \mathrm{~nm}$. We prepared a standard solution by dissolving the accurately weighed quantity of EFX-Ca (or EFX) into $\mathrm{H}_{2} \mathrm{O}$ at $35^{\circ} \mathrm{C}$ to achieve a primary standard solution. We diluted this solution into a series of working solutions to measure their UV-Vis spectra. We recorded each maximum absorbance found at $291 \mathrm{~nm}$ to give a standard curve according to the LambertBeer Law, as shown in Figure 2 and Figure S2 (ESIt). Then, we comparatively measured a saturated aqueous solution of EFX-Ca (or EFX) at $35^{\circ} \mathrm{C}$ and determined its corresponding concentration by fitting the standard curve.

\subsection{Antibacterial Activity Evaluation}

The clinically typical pathogens (Staphylococcus aureus, Escherichia coli, Pseudomonas aeruginosa, Salmonellosis typhoidal and Proteus vulgaris) were obtained from the Department of Microbiology and Immunology of Guangxi Medical University. We cultured the bacterial suspension of five pathogens in bouillon culture-medium at $37^{\circ} \mathrm{C}$, and diluted it into 0.5 McFarland Standard with bioclean normal saline (the volume ratio of each bacterial suspension and bioclean normal saline was 1:1000, and the concentration of bacterial suspension was $1 \sim 2 \times 10^{8} \mathrm{CFU} / \mathrm{mL}$ ). We selected EFX and EFX-Ca as the tested drugs before they were prepared to be $10^{-3} \mathrm{mg} / \mathrm{mL}$ by DMSO. We carried out the assays for MIC and MBC evaluation by doubling the dilution under sterile operation on the clean bench $[46,47]$. To be specific, we set the sterile test tubes numbered 1-10 for comparison according to the half-dilution method. We added the broth medium to each test tube to fix the final volume to be $2 \mathrm{~mL}$. Therefore, we prepared the final concentration of EFX-Ca or EFX in the tube nos. $1 \sim 9$ to be $1 / 4,1 / 8,1 / 16,1 / 32,1 / 64,1 / 128,1 / 256,1 / 512$, and 
$1 / 1204 \mu \mathrm{g} / \mathrm{mL}$. Then, we filled each tube with $50 \mu \mathrm{L}$ of inoculated bacteria colony, except for tube no. 9 , which was the negative control. The final colony concentration in each test tube was $2 \times 10^{5} \mathrm{CFU} / \mathrm{mL}$. Tube no. 10 was set as a blank without the tested drug. The samples were cultured at $37^{\circ} \mathrm{C}$ for $24 \mathrm{~h}$ before we obtained and observed results the next day. We repeated all tests in triplicate.

\subsection{Acute Toxicity Study}

All tests were conducted in the animal experimental center of Guangxi Medical University. Preliminary experiments were needed before starting official tests. The determination of different dosage groups $(16,000,10,556,6964,4595,3031$, and $2000 \mathrm{mg} / \mathrm{kg}$ ) in official tests was based on the maximum dose leading to no death and the minimum dose resulting in no survival, which we obtained from the pilot study [48,49]. Male and female KM mice (5-6 weeks old, 20-23 g weight) that were allowed free access to standard diet and tap water (with no antibacterial agents) were housed in a specific pathogen-free facility with conditions of constant photo period $\left(12 \mathrm{~h}\right.$ light $/ 12 \mathrm{~h}$ dark with $25-28^{\circ} \mathrm{C}$ temperature and 45-65\% humidity). Altogether, 210 mice were divided into 21 groups on average, and every 7 groups were set up for EFX, EFX-Ca and EFX-Na, respectively. Groups of mice ( $n=10$ per group, half male and half female) received different doses of the tested compounds by gavage at the same single dose of drug solution, which was uniformed to be $0.4 \mathrm{mg}$ (drug solution)/10 g, but containing different concentration of tested drugs. Then, all mice were fasted for $12 \mathrm{~h}$ with drinking water only. We compared these mice with the control group in which the mice were not given drugs, according to the pre-experimental procedure. We closely observed the mice for $6 \mathrm{~h}$ after the gavage for signs of toxicity and mortality. As soon as death occurred among the maximum-dose group, we conducted an autopsy and took samples from the main organs for histopathological examination. In addition, we monitored all of the tested mice for 2 weeks to record their weight and mortality [50].

\subsection{Histopathological Examination}

After the acute toxicity test, the dead mice after oral administration and the surviving mice at the end of the observation period were promptly dissected and pathologically examined. We checked whether the organ tissues of the animals exhibited hyperemia, hemorrhage, or other abnormal changes. We dissected the important organs (heart, liver, spleen, lung, kidney, large intestine, and small intestine) of dead mice and normal mice in the high-dose group of each drug solution. Then, the main organs were fixed in $10 \%$ buffered formalin and embedded in paraffin for 1-4 h. They were histopathologically examined under the optical microscope after slicing and staining with hematoxylineosin (HE) staining. No fixed parameters were compared between the treatment and control groups.

\subsection{Pharmacokinetic Assay}

\subsubsection{Feeding and Oral Administration on the Tested SD Rats}

Altogether, nine male SD rats (6-7 weeks old, 200-240 g weight) were allowed free access to standard diet and tap water (with no antibacterial agents) and were housed with conditions of constant temperature $\left(25-28{ }^{\circ} \mathrm{C}\right)$ and humidity $(45-65 \%)$. These rats were marked, randomly and equally divided into three groups, respectively, for EFX, EFX-Ca and control. They were further fasted for $12 \mathrm{~h}$ with drinking water only before the oral administration at a single dose of $10 \mathrm{mg} /(\mathrm{kg} \cdot \mathrm{bw})(\mathrm{EFX})$ and $12 \mathrm{mg} /(\mathrm{kg} \cdot \mathrm{bw})(\mathrm{EFX}-\mathrm{Ca})$. We compared these rats with the control group in which the rats were not given drugs [51-53].

\subsubsection{Working Conditions of HPLC-MS}

For the HPLC-MS measurement, we dissolved the standard EFX in the distilled water to prepare a $1.0 \mathrm{mg} / \mathrm{mL}$ standard working solution. Then, we dissolved EFX and the 
EFX-Ca in distilled water to prepare the stock solution of 1.0 and $1.2 \mathrm{mg} / \mathrm{mL}$, respectively. The detailed experimental working conditions are listed in Table S7.

\subsubsection{Blood Sample Collection and Pretreatment of the Plasma Sample by HPLC-MS}

We collected blood at different time points $(0,0.083,0.333,0.5,0.75,1,3,4,6,8,10$, 12 , and $24 \mathrm{~h}$ ) from the rat's eye socket vein in rotation after oral administration. Then, we separated the plasma by centrifugation at $4{ }^{\circ} \mathrm{C}, 3500 \mathrm{r} / \mathrm{min}$ and stored it at $-20{ }^{\circ} \mathrm{C}$ until detection.

Before the drug concentrations in plasma were detected, we first needed to obtain the optimal pretreatment of the plasma samples. We gained the specification curve according to the optimal pretreatment with the blank plasma and the standard working solution of EFX. During pretreatment, a mixture of blank plasma or medicated plasma (300 $\mu \mathrm{L})$, hexyl hydride $(2.5 \mathrm{~mL})$, and dichloromethane $(2.5 \mathrm{~mL})$ was centrifuged for the supernatant $(4.0 \mathrm{~mL})$ at $1000 \mathrm{r} / \mathrm{min}$. We dried the plasma by nitrogen blowing on a water bath at $40{ }^{\circ} \mathrm{C}$, dissolved it with the mobile phase $(300 \mu \mathrm{L})$, and extracted the supernatant for analysis after filtrating with $0.22 \mu \mathrm{M}$ ultra-filtration membrane. We made a series of plasma samples with different concentrations of $\operatorname{EFX}(0.025,0.05,0.1,0.5$, and $1 \mu \mathrm{L} / \mathrm{mL}$, which were marked on the $x$-axis) [51-54] by adding standard working solutions (30 $\mu \mathrm{L})$ of different concentrations into the blank plasma $(270 \mu \mathrm{L})$, and treated them in accordance with the previous method. Then, we recorded a series of peak areas ( $y$-axis) by HPLC-MS, to get the relationship between the $y$ - and $x$-axis. A linear equation for a standard curve of EFX, $y=19,373 x-72.512$, was thus achieved $\left(R^{2}=0.9997\right)$. From the above plasma matrix standard solution, the limit of detection (LOD) of EFX was determined to be $0.1 \mathrm{ng} / \mathrm{mL}$, based on the EFX concentration of the sample with Signal to Noise Ratio $(\mathrm{SNR})=3$. The limit of quantitation (LOQ) of EFX was determined to be $1.0 \mathrm{ng} / \mathrm{mL}$, based on the EFX concentration of the sample with $\mathrm{SNR}=10$. The standard curve and the relationship between drug concentration and the elimination time in plasma samples were formatted by Origin software. The main pharmacokinetic parameters, such as $\mathrm{Ke}, T_{\max }, C_{\max }, t_{1 / 2}$, $\mathrm{AUC}_{0-\mathrm{t}}$, etc., were calculated by WinNonlin (Version 5.2.1) software, and processed by the non-compartmental model.

\subsection{In Vivo Acute Toxicity and Anti-Inflammatory Effects on Zebrafish \\ 3.9.1. Preliminary Evaluation on the Acute Toxicity on Zebrafish}

The wild type AB strain zebrafish was further used for the preliminary evaluations of EFX-Ca on the acute toxicity on zebrafish. Zebrafish were incubated and grown in the Joint Laboratory established by Shandong Rui'ying Pharmaceutical Group (Heze, China) and China Pharmaceutical University. Both the Wild-type AB (Danio rerio) and Tg(mpx:eGFP) zebrafish strains were maintained under the guidance of the standard procedures of The Zebrafish Book [55]. Adult zebrafish were incubated under the optimized conditions $\left(28.5 \pm 0.5{ }^{\circ} \mathrm{C}, \mathrm{pH}=7.5\right.$, light $(14 \mathrm{~h}) /$ dark $(10 \mathrm{~h})$ per day) and fed brine shrimp twice a day. In order to obtain the embryos, firstly, the healthy zebrafish, female and male each half and separated by clapboard for $12 \mathrm{~h}$ before the experiment, were chosen the night before and were kept in the spawning tank. Then the zebrafish were allowed to naturally mate and spawn the next morning. The normally born embryos were then collected after $1 \mathrm{~h}$ and kept in an incubating system at $28^{\circ} \mathrm{C}$. The $6 \mathrm{hpf}$ (hour post fertilization) embryos were transferred into a 6-well plate exposed to $5 \mathrm{~mL}$ of egg water, in which 30 embryos were in each well. Then different concentrations $(0.01,0.1,1,10,20 \mu \mathrm{M})$ of the tested EFX-Ca, compared with EFX itself, were added into each well, along with a well set as blank control. The zebrafish's developmental status, abnormalities (such as body length, pericardial edema, spinal curvature) and death numbers were then carefully observed under stereoscopic microscope and recorded at the time points of 6, 24, 48, 72, 96 and $120 \mathrm{hpf}$ of the embryos, respectively. 


\subsubsection{In Vivo Anti-Inflammation Assay in Zebrafish}

The transgenic zebrafish line $\operatorname{Tg}(\mathrm{mpx}: \mathrm{eGFP})$ with green fluorescence at $3 \mathrm{dpf}$ (day post fertilization) were primarily used for the anti-inflammation evaluation effect of EFX-Ca. This zebrafish model was set and induced by 40 min of incubation of $10 \mu \mathrm{M}$ of $\mathrm{CuSO}_{4}$. Before the $\mathrm{CuSO}_{4}$-induced model was build, the $\mathrm{Tg}$ (mpx:eGFP) zebrafish were primarily incubated with different concentrations of EFX-Ca, also in comparison with EFX for $1 \mathrm{~h}$, of $0.01,0.1$ and $1 \mu \mathrm{M}$, respectively, based on the above results of preliminary acute toxicity evaluation. The ROS production induced by $\mathrm{CuSO}_{4}$ in zebrafish could then be probed and visualized by the migration and aggregation on those labeled neutrophils. The zebrafish were also photographed under the stereo microscope.

The wild-type $\mathrm{AB}$ zebrafish at $5 \mathrm{dpf}$ (day post fertilization) were further used for another anti-inflammation model induced by $\mathrm{H}_{2} \mathrm{O}_{2}$ to evaluate the anti-inflammation effect of EFX-Ca. In the experiment, 15 embryos were set in each well of the 6-well plate, and the incubated concentrations of EFX-Ca, compared with EFX, were fixed at 0.01, 0.1 and $1 \mu \mathrm{M}$, respectively. After $48 \mathrm{~h}$ of incubation with different concentrations of EFX-Ca or EFX, each medicated bath solution was eluted by egg water three times, then followed by the incubation of $\mathrm{H}_{2} \mathrm{O}_{2}(1.0 \mathrm{mM})$ for $4 \mathrm{~h}$. The $\mathrm{H}_{2} \mathrm{O}_{2}$-containing solution was eluted again and then DCFH-DA $(10 \mu \mathrm{M})$ was added into the new egg water solution in darkness to label the potential induced ROS in zebrafish for $30 \mathrm{~min}$. Then the fluorescence emission of DCF-DA oxidized by the formed ROS in zebrafish could be visualized and photographed under the stereo microscope.

\subsection{Quasi-Clinical Trials on Broilers}

We purchased 500 4-week-old broilers in two types: AA white feather broilers (AA) and 817 hybrid broilers (817) from Kang'da Livestock and Poultry Co., Ltd. Anhydrous dextrose was purchased from Xi'wang Pharmaceutical Co., Ltd. We prepared the 5\% EFX and EFX-Ca mixed with anhydrous dextrose as the oral liquid for the therapeutic trial. Before the trial, all chickens that were allowed a standard diet and tap water (with no antibacterial agents) were housed for a week in a specific pathogen-free facility with conditions of illumination $(24 \mathrm{~h})$, desiccation, temperature $\left(25-28^{\circ} \mathrm{C}\right)$, and ventilation. Then, broilers were randomly and equally divided into five different groups and marked as five groups. For the AA broilers, the groups included the following: high dosage of EFX-Ca (14 g drug/1.5 kg feed), medium dosage of EFX-Ca (9 $\mathrm{g} \mathrm{drug/1.5} \mathrm{kg} \mathrm{feed),} \mathrm{low} \mathrm{dosage} \mathrm{of}$ EFX-Ca (6 g drug $/ 1.5 \mathrm{~kg}$ feed), and single dosage of EFX (11 g drug/1.5 kg feed), and the control group. It should be noted that the " $\mathrm{g} \mathrm{drug"} \mathrm{in} \mathrm{the} \mathrm{administration} \mathrm{unit} \mathrm{(} \mathrm{g}$ drug/ $\mathrm{kg}$ feed) refers to the drug solution containing 5\% EFX-Ca or EFX. For the 817 broilers, the feed amount in each group was decreased to $0.75 \mathrm{~kg}$. Note that the daily drug-mixed feeding ratio ( $\mathrm{g}$ drug $/ \mathrm{kg}$ feed) was indicated for the first $4 \mathrm{~h}$ every day, and unmedicated feed then followed. The experimental data are detailed in Table 9. In addition, E. coli strains for the infection of chicken was supplied as a freeze-dried powder. They were revived and cultured according to the standard procedures. The strain was inoculated into a liquid medium and cultured in a $37^{\circ} \mathrm{C}$ incubator for $6-8 \mathrm{~h}$. We detected the concentration of the bacterial liquid to be $2.8 \times 10^{8} \mathrm{CFU} / \mathrm{mL}$ as the pathogenic concentration. Finally, all of the chickens except the healthy control group were intramuscularly injected with $0.5 \mathrm{~mL}$ of pathogenic bacteria, and all chickens were fasted for $4 \mathrm{~h}$. After successfully simulating the bacterial infection of the chickens, the drug-mixed feeding chickens were continuously fed for $6 \mathrm{~d}$. During this time, we observed their behavioral habits, mortality, and recovery rates. 
Table 9. Conditions for the drug-mixed feeding on two types of tested broilers.

\begin{tabular}{ccccc}
\hline $\begin{array}{c}\text { Type of } \\
\text { Broilers }\end{array}$ & Conditions & $\begin{array}{c}\text { Compound in Each } \\
\text { Group }\end{array}$ & Number & $\begin{array}{c}\text { Dosage } \\
\text { (Drug in Solution + Feed)/4 h }\end{array}$ \\
\hline \multirow{3}{*}{ AA } & Uninfected & Control & 50 & $1.5 \mathrm{~kg}$ \\
& infected & EFX & 50 & $11 \mathrm{~g}+1.5 \mathrm{~kg}$ \\
& infected & EFX-Ca (High) & 50 & $14 \mathrm{~g}+1.5 \mathrm{~kg}$ \\
& infected & EFX-Ca (Medium) & 50 & $9 \mathrm{~g}+1.5 \mathrm{~kg}$ \\
& infected & EFX-Ca (Low) & 50 & $6 \mathrm{~g}+1.5 \mathrm{~kg}$ \\
\hline \multirow{3}{*}{817} & Uninfected & Control & 50 & $0.75 \mathrm{~kg}$ \\
& infected & EFX & 50 & $11 \mathrm{~g}+0.75 \mathrm{~kg}$ \\
& infected & EFX-Ca (High) & 50 & $9 \mathrm{~g}+0.75 \mathrm{~kg}$ \\
& infected & EFX-Ca (Medium) & 50 & $6 \mathrm{~g}+0.75 \mathrm{~kg}$ \\
\hline
\end{tabular}

Note: For each group, each broiler was orally gavaged the medicated feed for the first $4 \mathrm{~h}$ daily and then followed by unmedicated feed. The feed was mixed with $5 \%$ drug contained in an aqueous solution, in which $11 \mathrm{mg}$ EFX or 14, 9, $6 \mathrm{mg}$ EFX-Ca, respectively, was added for each broiler. The unit in the last column (g drug in solution/ $\mathrm{kg}$ feed) refers to the medicated aqueous solution containing 5\% EFX-Ca or EFX.

\section{Conclusions}

Overall, viewed from the results above, it has been demonstrated that the combination of the appropriate metal ions and drugs could improve the efficacy of the original drug and reduce the toxicity. This calcium complex of EFX might be partly recognized, but not limited, as a modified or derived compound from EFX. However, it is indeed a new agent when introducing the bio-safe $\mathrm{Ca}$ (II) to EFX based on coordination chemistry, which showed superiority over EFX for lower in vivo toxicity and higher therapeutic efficacy on the tested mice and two broiler strains. Although the detailed molecular mechanism and key role of the central $\mathrm{Ca}$ (II) in exerting better efficacy remain to be further investigated, the present research findings demonstrated that combining the appropriate and biocompatible macrometallic element with organic veterinary drugs on the chemical level had immeasurable potential to improve therapeutic efficacy. This study indicated a promising pathway for the development of new metal-based veterinary drugs.

Supplementary Materials: The following supporting information can be downloaded at: https: / / www.mdpi.com/article/10.3390/pharmaceutics14020249/s1, Figure S1: The packing diagram of the crystal structure of EFX-Ca viewed along the b-axis showing the $\mathrm{C}-\mathrm{H}$... O hydrogen bonding (indicated by the dashed lines) as well as the $\pi-\pi$ stacking interactions between the neighboring EFX ligands; Figure S2: The water solubility of EFX at room temperature was determined by the Lambert-Beer's Law based on the standard line of the water solubility of EFX derived from a series of prepared d concentrations. The concentration of the working solution of EFX indicated by the UV-Vis spectrum was based on a $30 \times$ dilution on the saturated aqueous solution of EFX; Figure S3: The time-dependent effects of the oral administration of EFX on the body weight of the tested KM mice; Figure S4: The time-dependent effects of the oral administration of EFX-Na on the body weight of the tested KM mice; Figure S5: The standard curve recorded by HPLC for the relationship between the concentrations and the peak area of EFX in the tested SD rats; Figure S6: The survival rate of the tested zebrafish under the medicated bath of different concentrations $(0.01,0.1,1,10,20 \mu \mathrm{M})$ of EFX-Ca or EFX; Figure S7: The preliminary acute toxicity evaluation of EFX-Ca, compared with EFX, at same concentrations $(0.01,0.1,1 \mu \mathrm{M})$ on zebrafish and observed directly by the stereo microscope; Figure S8: The other two examined zebrafish with similar results of the inhibition effect of EFX-Ca, on the observed neutrophil cluster aggregation under the CuSO4-induced mode of the transgenic zebrafish line Tg (mpx: eGFP); The partial magnified images of the latter part of the zebrafish were shown on the right side; Figure S9: The other two examined zebrafish with similar results of the inhibition effect of EFX, on the observed neutrophil cluster aggregation under the $\mathrm{CuSO}_{4}$-induced mode of the transgenic zebrafish line Tg (mpx: eGFP); The partial magnified images of the latter part of the zebrafish were shown on the right side; Figure S10: The other two examined zebrafish with similar results of the anti-inflammatory effect of EFX-Ca on the $\mathrm{H}_{2} \mathrm{O}_{2}$-induced ROS production in zebrafish model, indicated by the green fluorescence probed and visualized by the added DCFH-DA; Figure S11: The other two examined zebrafish with similar results of the anti-inflammatory effect of EFX on the $\mathrm{H}_{2} \mathrm{O}_{2}$-induced ROS production in zebrafish model, indicated by the green fluores- 
cence probed and visualized by the added DCFH-DA; Figure S12: General clinical observations on the infected chicken showing the characteristic pathological features $(C, D, E, F)$ during the oral administration of EFX-Ca, compared with the uninfected chicken with normal symptoms (A, B); Figure S13: The partial pathologic anatomy of the infected chickens that died after the oral administration of EFX-Ca; Figure S14: The IR spectrum of EFX-Ca; Figure S15: The ESI-MS spectrum of EFX-Ca; Table S1: The selected bond lengths $(\AA)$ and bond angles $\left(^{\circ}\right)$ for EFX-Ca; Table S2: Changes in body weight of KM mice caused by EFX ( $\mathrm{g}, \pm \mathrm{s})$; Table S3: Changes in body weight of KM mice caused by EFX-Na $(\mathrm{g}, \pm \mathrm{s})$; Table S4: The relationship between the concentrations and the corresponding peak area of EFX in the tested SD rats recorded by HPLC; Table S5: Drug concentration in plasma at different time points after the administration of EFX and EFX-Ca in the tested SD rats; Table S6: The working conditions for HPLC-MS.

Author Contributions: Conceptualization, Y.-C.L. and H.L.; Data curation, H.-T.Y., R.-X.L., Q.-Z.Y., H.-C.L., R.-F.G. and L.-H.W.; Formal analysis, H.-T.Y., R.-X.L. and L.-H.W.; Investigation, Y.-C.L. and H.-T.Y.; Methodology, Y.-C.L., H.-T.Y. and L.-M.L.; Writing-original draft, H.-T.Y. and Q.-Z.Y.; Writingreview \& editing, Y.-C.L. and R.-X.L.; Supervision, Y.-C.L., L.-M.L. and H.L.; Fund acquisition, Y.-C.L. and H.L. All authors have read and agreed to the published version of the manuscript.

Funding: This work was financially supported by the Natural Science Foundation of Guangxi Province (No. 2017GXNSFDA198048, 2020AB26003) and the National Natural Science Foundation of China (No. 21561005, 21431001).

Institutional Review Board Statement: The study was approved by The Animal Care \& Welfare Committee of Guangxi Medical University, Nanning, China (Permit Number: 201808073) on 12 September 2018.

Informed Consent Statement: Not applicable.

Data Availability Statement: The data presented in this study are available in this article and related Supplementary Material. CCDC No. 2013726 for the calcium(II) complex of enrofloxacin, EFX-Ca, contains the supplementary crystallographic data for this paper. The data can be obtained free of charge via http:/ / www.ccdc.cam.ac.uk, accessed on 15 January 2022, or from the Cambridge Crystallographic Data Centre, 12 Union Road, Cambridge CB21EZ, UK (Fax: +44-1223-336-033; E-mail: deposit@ccdc.cam.ac.uk).

Acknowledgments: The authors thank Fu-Ping Huang for the X-ray single crystal diffraction analysis on the title complex. We also thank LetPub (www.letpub.com) for its linguistic assistance during the preparation of this manuscript.

Conflicts of Interest: The authors declare no competing interest in this work.

\section{Abbreviations}

AUC: Area Under Curve; CCD: charge-coupled device; CFU: colony forming unit; DMSO: dimethyl sulfoxide; E. coli: Escherichia coli; EFX: Enrofloxacin; EFX-Ca: The calcium(II) complex of enrofloxacin; EFX-Na: The sodium salt of enrofloxacin; ESI-MS: Electrospray ionization-mass spectrometer; FQN: Fluoroquinolone; FT-IR: Fourier Transform Infrared Spectroscopy; HE: Hematoxylineosin; HPLC-MS: High Performance Liquid Chromatography-Mass Spectrometry; IOD: Integrated Optical Density; KM mice: Kunming mice; $\mathrm{LD}_{50}$ : median lethal dose on fifty percent; LOD: limit of detection; LOQ: limit of quantitation; MBC: minimum bactericidal concentration; MIC: minimum inhibitory concentration; P. aeruginosa: Pseudomonas aeruginosa; P. vulgaris: Proteus vulgaris; S. aureus: Staphylococcus aureus; S. Typhi: Salmonellosis typhoidal; SNR: Signal to Noise Ratio; ROS: reactive oxygen species; UV-Vis: Ultraviolet-visible.

\section{References}

1. Andersson, M.I.; MacGowan, A.P. Development of the quinolones. J. Antimicrob. Chemoth. 2003, 51, 1-11. [CrossRef] [PubMed]

2. Hu, Y.Q.; Zhang, S.; Xu, Z.; Lv, Z.S.; Liu, M.L.; Feng, L.S. 4-Quinolone hybrids and their antibacterial activities. Eur. J. Med. Chem. 2017, 141, 335-345. [CrossRef] [PubMed]

3. Gootz, T.D.; Brighty, K.E. Fluoroquinolone antibacterials: SAR, mechanism of action, resistance, and clinical aspects. Med. Res. Rev. 1996, 16, 433-486. [CrossRef] 
4. Bisacchi, G.S. Origins of the quinolone class of antibacterials: An expanded "discovery story". J. Med. Chem. 2015, 58, 4874-4882. [CrossRef]

5. Norris, S.; Mandell, G.L. The quinolones: History and overview. In The Quinolones; Academic Press: Cambridge, MA, USA, 1988; pp. 1-22.

6. Appelbaum, P.C.; Hunter, P.A. The fluoroquinolone antibacterials: Past, present and future perspectives. Int. J. Antimicrob. Agents 2000, 16, 5-15. [CrossRef]

7. Kohanski, M.A.; Dwyer, D.J.; Collins, J.J. How antibiotics kill bacteria: From targets to networks. Nat. Rev. Microbiol. 2010, 8 , 423-435. [CrossRef]

8. Dighe, S.N.; Collet, T.A. Recent advances in DNA gyrase-targeted antimicrobial agents. Eur. J. Med. Chem. 2020, 199, 112326. [CrossRef]

9. $\mathrm{Wu}$, P.; Lawrence, L.E.; Denbleyker, K.L.; Barrett, J.F. Mechanism of action of the des-F(6) quinolone BMS-284756 measured by supercoiling inhibition and cleavable complex assays. Antimicrob. Agents Chemother. 2001, 45, 3660-3662. [CrossRef]

10. Nakamura, S. Mechanisms of Quinolone Resistance. J. Infect. Chemother. 1997, 3, 128-138. [CrossRef]

11. Zhang, G.F.; Liu, X.; Zhang, S.; Pan, B.; Liu, M.L. Ciprofloxacin derivatives and their antibacterial activities. Eur. J. Med. Chem. 2018, 146, 599-612. [CrossRef]

12. Costa, J.C.M.; de Freitas Espeschit, I.; Pieri, F.A.; dos Anjos Benjamin, L.; Moreira, M.A.S. Increased production of biofilms by Escherichia coli in the presence of enrofloxacin. Vet. Microbiol. 2012, 160, 488-490. [CrossRef] [PubMed]

13. Pasquali, F.; Manfreda, G. Mutant prevention concentration of ciprofloxacin and enrofloxacin against Escherichia coli, Salmonella Typhimurium and Pseudomonas aeruginosa. Vet. Microbiol. 2007, 119, 304-310. [CrossRef] [PubMed]

14. Macedo, N.; Cheeran, M.C.J.; Rovira, A.; Holtcamp, A.; Torremorell, M. Effect of enrofloxacin on Haemophilus parasuis infection, disease and immune response. Vet. Microbiol. 2017, 199, 91-99. [CrossRef] [PubMed]

15. Domagala, J.M. Structure-activity and structure-side-effect relationships for the quinolone antibacterials. J. Antimicrob. Chemother. 1994, 33, 685-706. [CrossRef] [PubMed]

16. Drlica, K.; Malik, M.; Kerns, R.J.; Zhao, X.L. Quinolone-mediated bacterial death. Antimicrob. Agents Chem. 2008, 52, 385-392 [CrossRef]

17. Wang, Y.; Liu, B.; Li, J.; Gong, S.; Dong, X.; Mao, C.; Yi, L. LuxS/AI-2 system is involved in fluoroquinolones susceptibility in Streptococcus suis through overexpression of efflux pump SatAB. Vet. Microbiol. 2019, 233, 154-158. [CrossRef] [PubMed]

18. Mücke, M.M.; Mayer, A.; Kessel, J.; Mücke, V.T.; Bon, D.; Schwarzkopf, K.; Rüschenbaum, S.; Queck, A.; Göttig, S.; Vermehren, A.; et al. Quinolone and multidrug resistance predicts failure of antibiotic prophylaxis of spontaneous bacterial peritonitis. Clin. Infect. Dis. 2020, 70, 1916-1924. [CrossRef] [PubMed]

19. Dougherty, T.J.; Beaulieu, D.; Barrett, J.F. New quinolones and the impact on resistance. Drug Discov. Today 2001, 6, 529-536. [CrossRef]

20. Turel, I.; Kljun, J.; Perdih, F.; Morozova, E.; Bakulev, V.; Kasyanenko, N.; Byl, J.A.W.; Osheroff, N. First ruthenium organometallic complex of antibacterial agent ofloxacin. Crystal structure and interactions with DNA. Inorg. Chem. 2010, 49, 10750-10752. [CrossRef]

21. Vinuelas-Zahinos, E.; Luna-Giles, F.; Torres-Garcia, P.; Fernandez-Calderon, M.C. Co(III), Ni(II), Zn(II) and Cd(II) complexes with 2-acetyl-2-thiazoline thiosemicarbazone: Synthesis, characterization, X-ray structures and antibacterial activity. Eur. J. Med. Chem. 2011, 46, 150-159. [CrossRef]

22. Rostamizadeh, S.; Daneshfar, Z.; Moghimi, H. Synthesis of sulfamethoxazole and sulfabenzamide metal complexes; evaluation of their antibacterial activity. Eur. J. Med. Chem. 2019, 171, 364-371. [CrossRef]

23. Naz, A.; Arun, S.; Narvi, S.S.; Alam, M.S.; Singh, A.; Bhartiya, P.; Dutta, P.K. Cu(II)-carboxymethyl chitosan-silane schiff base complex grafted on nano silica: Structural evolution, antibacterial performance and dye degradation ability. Int. J. Biol. Macromol. 2018, 110, 215-226. [CrossRef]

24. Tan, L.; Zhou, X.; Wu, K.; Yang, D.; Jiao, Y.; Zhou, C. Tannic acid/Ca(II) anchored on the surface of chitin nanofiber sponge by layer-by-layer deposition: Integrating effective antibacterial and hemostatic performance. Int. J. Biol. Macromol. 2020, 159, 304-315. [CrossRef]

25. Turel, I. The interactions of metal ions with quinolone antibacterial agents. Coord. Chem. Rev. 2002, 232, 27-47. [CrossRef]

26. Chen, Z.-F.; Xiong, R.-G.; Zuo, J.-L.; Guo, Z.; You, X.-Z.; Fun, H.-K. X-ray crystal structures of $\mathrm{Mg}^{2+}$ and $\mathrm{Ca}^{2+}$ dimers of the antibacterial drug norfloxacin. J. Chem. Soc. Dalton Trans. 2000, 4013-4014. [CrossRef]

27. Psomas, G.; Kessissoglou, D.P. Quinolones and non-steroidal anti-inflammatory drugs interacting with copper(II), nickel(II), cobalt(II) and zinc(II): Structural features, biological evaluation and perspectives. Dalton Trans. 2013, 42, 6252-6276. [CrossRef] [PubMed]

28. Clapham, D.E. Calcium signaling. Cell. 2007, 131, 1047-1058. [CrossRef]

29. Stewart, T.A.; Yapa, K.T.D.S.; Monteith, G.R. Altered calcium signaling in cancer cells. Biochim. Biophys. Acta 2015, $1848,2502-2511$. [CrossRef]

30. Cui, C.; Merritt, R.; Fu, L.; Pan, Z. Targeting calcium signaling in cancer therapy. Acta Pharm. Sin. B 2017, 7, 3-17. [CrossRef] [PubMed]

31. Katz, A.K.; Glusker, J.P.; Beebe, S.A.; Bock, C.W. Calcium ion coordination: A comparison with that of beryllium, magnesium, and zinc. J. Am. Chem. Soc. 1996, 118, 5752-5763. [CrossRef] 
32. Xie, Y.J.; Yu, M.X.; Yang, Q.Z.; Liu, Y.C.; Liu, R.X.; Dong, J.X.; Wu, X.Y.; Guo, R.F.; Pan, Y.X.; Chen, Z.F.; et al. A new calcium(II) complex of marbofloxacin showing much lower acute toxicity with retained antibacterial activity. J. Inorg. Biochem. 2020, 203, 110905. [CrossRef]

33. Van Wijk, R.C.; Krekels, E.H.J.; Hankemeier, T.; Spaink, H.P.; van der Graaf, P.H. Systems pharmacology of hepatic metabolism in zebrafish larvae. Drug Discov. Today Dis. Models 2016, 22, 27-34. [CrossRef]

34. MacRae, C.A.; Peterson, R.T. Zebrafish as tools for drug discovery. Nat. Rev. Drug Discov. 2015, 14, 721-731. [CrossRef] [PubMed]

35. Cassar, S.; Adatto, I.; Freeman, J.L.; Gamse, J.T.; Iturria, I.; Lawrence, C.; Muriana, A.; Peterson, R.T.; Van Cruchten, S.; Zon, L.I. Use of zebrafish in drug discovery toxicology. Chem. Res. Toxicol. 2020, 33, 95-118. [CrossRef] [PubMed]

36. Guo, R.F.; Yan, H.T.; Liu, R.X.; Li, H.C.; Liu, Y.C.; Chen, Z.F.; Liang, H. Structural characterization and pharmacological assessment in vitro/in vivo of a new copper(II)-based derivative of enrofloxacin. Metallomics 2020, 12, 2145. [CrossRef]

37. D'Alençon, C.A.; Peña, O.A.; Wittmann, C.; Gallardo, V.E.; Jones, R.A.; Loosli, F.; Liebel, U.; Grabher, C.; Allende, M.L. A high-throughput chemically induced inflammation assay in zebrafish. BMC Biol. 2010, 8, 151. [CrossRef]

38. Cruz, F.F.; Leite, C.E.; Kist, L.W.; de Oliveira, G.M.; Bogo, M.R.; Bonan, C.D.; Campos, M.M.; Morrone, F.B. Effects of caffeine on behavioral and inflammatory changes elicited by copper in zebrafish larvae: Role of adenosine receptors. Comp. Biochem. Physiol. Part C Toxicol. Pharmacol. 2017, 194, 28-36. [CrossRef] [PubMed]

39. Leite, C.E.; de Oliveira Maboni, L.; Cruz, F.F.; Rosemberg, D.B.; Zimmermann, F.F.; Pereira, T.C.B.; Bogo, M.R.; Bonan, C.D.; Campos, M.M.; Morrone, F.B.; et al. Involvement of purinergic system in inflammation and toxicity induced by copper in zebrafish larvae. Toxicol. Appl. Pharmacol. 2013, 272, 681-689. [CrossRef]

40. Wang, L.P.; Guo, Y.G.; Shi, X.L.; Chen, S.F. Different antibiotics-induced morphological changes and free endotox in release in $E$. coli. Chin. J. Vet. Sci. 2004, 24, 596-599.

41. Wyckoff, T.J.O.; Raetz, C.R.H.; Jackman, J.E. Antibacterial and anti-inflammatory agents that target endotoxin. Trends Microbiol. 1998, 6, 154-159. [CrossRef]

42. Fraeyman, S.; Devreese, M.; Broekaert, N.; De Mil, T.; Antonissen, G.; De Baere, S.; De Backer, P.; Rychlik, M.; Croubels, S. Quantitative determination of tenuazonic acid in pig and broiler chicken plasma by LC-MS/MS and its comparative toxicokinetics. J. Agric. Food Chem. 2015, 63, 8560-8567. [CrossRef]

43. Thorsted, A.; Tano, E.; Kaivonen, K.; Sjlin, J.; Nielsen, E.I. Extension of pharmacokinetic/pharmacodynamic (PK/PD) time-kill studies to include LPS/endotoxin release from E. coli exposed to cefuroxime. Antimicrob. Agents Ch. 2020, 64, e02070-19. [CrossRef]

44. Tamaoki, J.; Sakai, N.; Tagaya, E.; Konno, K. Macrolide antibiotics protect against endotoxin-induced vascular leakage and neutrophil accumulation in rat trachea. Antimicrob. Agents Ch. 1994, 38, 1641-1643. [CrossRef] [PubMed]

45. Sheldrick, G.M. SHELXL-97, Program for Crystal Structure Solution; University of Göttingen: Göttingen, Germany, $1997 ;$ p. 36.

46. Takeoka, Y.; Tanino, T.; Sekiguchi, M.; Yonezawa, S.; Sakagami, M.; Takahashi, F.; Togame, H.; Tanaka, Y.; Takemoto, H.; Ichikawa, S.; et al. Expansion of antibacterial spectrum of muraymycins toward Pseudomonas aeruginosa. ACS Med. Chem. Lett. 2014, 5, 556-560. [CrossRef] [PubMed]

47. Novaković, I.; Anđelković, U.; Zlatović, M.; Gašić, M.J.; Sladić, D. Bioconjugate of lysozyme and the antibacterial marine sesquiterpene quinone avarone and its derivatives. Bioconjug. Chem. 2012, 23, 57-65. [CrossRef] [PubMed]

48. Piyachaturawat, P.; Glinsukon, T.; Toskulkao, C. Acute and subacute toxicity of piperine in mice, rats and hamsters. Toxicol. Lett. 1983, 16, 351-359. [CrossRef]

49. Sosa, S.; Del Favero, G.; De Bortoli, M.; Vita, F.; Soranzo, M.R.; Beltramo, D.; Ardizzone, M.; Tubaro, A. Palytoxin toxicity after acute oral administration in mice. Toxicol. Lett. 2009, 191, 253-259. [CrossRef]

50. Kasprzak, K.S.; Diwan, B.A.; Kaczmarek, M.Z.; Logsdon, D.L.; Fivash, M.J.; Salnikow, K. Effects of ascorbic acid on carcinogenicity and acute toxicity of nickel subsulfide, and on tumor transplants growth in gulonolactone oxidase knock-out mice and wild-type C57BL mice. Toxicol. Appl. Pharmacol. 2011, 257, 32-37. [CrossRef]

51. Wang, J.; Zhou, G.; Chen, C.; Yu, H.; Wang, T.; Ma, Y.; Jia, G.; Gao, Y.; Li, B.; Sun, J.; et al. Acute toxicity and biodistribution of different sized titanium dioxide particles in mice after oral administration. Toxicol. Lett. 2007, 168, 176-185. [CrossRef]

52. Wang, B.; Feng, W.Y.; Wang, T.C.; Jia, G.; Wang, M.; Shi, J.W.; Zhang, F.; Zhao, Y.L.; Chai, Z.F. Acute toxicity of nano- and micro-scale zinc powder in healthy adult mice. Toxicol. Lett. 2006, 161, 115-123. [CrossRef]

53. Kpemissi, M.; Metowogo, K.; Melila, M.; Veerapur, V.P.; Negru, M.; Taulescu, M.; Potarniche, A.V.; Suhas, D.S.; Puneeth, T.A.; Vijayakumar, S.; et al. Acute and subchronic oral toxicity assessments of combretum micranthum (Combretaceae) in Wistar rats. Toxicol. Rep. 2020, 7, 162-168. [CrossRef] [PubMed]

54. Siebenbuerger, L.; Hernandez-Olmos, V.; Abdelsamie, A.S.; Frotscher, M.; van Koppen, C.J.; Marchais-Oberwinkler, S.; Scheuer, C.; Laschke, M.W.; Menger, M.D.; Boerger, C.; et al. Highly potent 17beta-HSD2 inhibitors with a promising pharmacokinetic profile for targeted osteoporosis therapy. J. Med. Chem. 2018, 61, 10724-10738. [CrossRef] [PubMed]

55. Westerfield, M. The Zebrafish Book, 3rd ed.; University of Oregon Press: Eugene, OR, USA, 1995. 